Reference NBSIR 82-1668

\title{
MEASUREMENT UNCERTAINTIES OF LEVEL GAGES FOR LIQUEFIED NATURAL GAS
}

\section{J. D. Siegwarth}

National Bureau of Standards U.S. Department of Commerce Boulder, Colorado 80303 June 1982 

NBSIR 82-1668

ATOWAL EUSEA

OF ERANDARDE

HTHAT

\section{MEASUREMENT UNCERTAINTIES \\ OF LEVEL GAGES FOR LIQUEFIED \\ NATURAL GAS}

foll 27198

J. D. Siegwarth

Thermophysical Properties Division

National Engineering Laboratory

National Bureau of Standards

U.S. Department of Commerce

Boulder, Colorado 80303

June 1982

Prepared for:

The Maritime Administration

U.S. Department of Commerce

Washington, D.C.

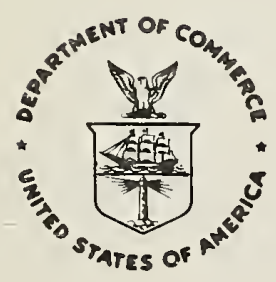

U.S. DEPARTMENT OF COMMERCE, Malcolm Baldrige, Secretary 
$-$ 
1. INTRODUCTION-

2. GAGE TYPES-

2. 1 CAPACITANCE GAGE-

2.2 CABLE GAGE--

2.3 BUBBLER GAGE-- 3 -

3. CAPACITANCE TYPE LEVEL GAGES-

3. 1 GENERAL DESCRIPTION OF GAGES

3.2 FIRST CAPACITANCE GAGE

3.2. 1 GAGE DESCRIPTION-_

3.2.2 MEASUREMENT UNCERTAINTIES

3.3. SECOND CAPACITANCE GAGE-

3.3. 1 GAGE DESCRIPTION-

3.3.2 MEASUREMENT UNCERTAINTIES-

3.4 DISCUSSION-

4. CABLE GAGE TESTS-

4. 1 INTRODUCTION-

4.1.1 GAGE ACCURACY TEST FACILITY

4.1.2 HYSTERESIS TEST FACILITY

4.2 FIRST CABLE GAGE, SERVO-

4.2.1 GAGE DESCRIPTION-

4.2.2 ACCURACY TESTS--

4.2.3 HYSTERESIS TESTS-

4.3 SECOND CABLE GAGE, SERVO

4.3.1 GAGE DESCRIPTION-

4.3.2 ACCURACY TESTS-

4.3.3 HYSTERESIS TESTS-

4.4 THIRD CABLE GAGE, SERVO

4.4.1 GAGE DESCRIPTION-

4.4.2 ACCURACY TESTS-

4.4.3 HYSTERESIS TESTS-

4.5 FOURTH CABLE GAGE, AUTOMATIC

4.5.1 GAGE DESCRIPTION-

4.5.2 ACCURACY TESTS TO A SOLID SURFACE-

4.5.3 ACCURACY TO A LIQUID SURFACE AND HYSTERESIS TESTS

5. BUBBLER TYPE LEVEL GAGES-

5.1 GAGE DESCRIPTION-

5.2 MEASUREMENT ERROR-

5.3 CONCLUSIONS, BUBBLER GAGE-

6. CONCLUSIONS-- CAPACITANCE GAGS

6. 1 CAPACITANCE GAGES- CABLE GAGES

6.2 CABLE GAGES- 12

6.3 BUBBLER GAGES-

7. ACKNOWLEDGMENTS

8. REFERENCES - 31

APPENDIX A-

APPENDIX B- 
type. These types are described in more detail in Section 2 and in later sections. The capacitance type is generally used as the primary gage for custody transfer while the cable gage or the bubbler usually serves as a back up gage. Gaging methods used for small tanks such as truck tanks are not included in this study.

In this report the measurement uncertainties of some representative gages of the three types have been measured or estimated from available information. Level gaging for custody transfer is assumed to take place when the tank level is static so the liquid surface is relatively quiet. Gage accuracy when the surface is moving is not estimated. Some of the gaging devices are too slow to even follow the liquid surface if the tank is rapidly filled. The uncertainty and hysteresis of four different types of cable gages have been measured at ambient conditions. These tests and the results are described in Section 4.

Because the measurement of level by capacitance gages and bubbler gages depend on bulk parameters rather than the difference between liquid and vapor, as do the cable gages, adequate testing requires the use of a liquid. The liquid, if the gage is used in LNG, should be LNG. No facility presently exists that is capable of such measurements. Limited resources precluded such tests in this work. The measurement uncertainties for capacitance gages, Section 3, and bubbler gages, Section 5, have been estimated from existing information. The temperature within a tank and the external environment affect cable gage accuracies. The uncertainties introduced into cable gage measurements by the environment and ways of eliminating them are covered in Appendix A.

\section{GAGE TYPES}

\subsection{CAPACITANCE GAGE}

Capacitance level gages are conceptually simple devices. One type has been described in the literature [18]. They are cylindrical capacitors consisting of two uniform coaxial tubes whose total capacitance is proportional to length if end effects are neglected. A vertical coaxial capacitor in vacuum has a capacitance of $C_{1}$. If this capacitor is filled with a dielectric 1 iquid to a height $h$, then

$$
c=2 \pi h\left(\varepsilon_{\ell}-1\right) 1 n b / a+c_{1}=h C_{1 j q}+C_{1}
$$

where $\varepsilon_{0}$ is the dielectric constant of the liquid, $b$ and a are the outer tube ID and inner tube OD respectively, and $C_{1}$ is the capacitance over and above the vacuum value added by the 1 iquid dielectric. Actually, the empty portion of the gage contains a gas so $\varepsilon_{0}-1$ is replaced by $\varepsilon_{\ell}-\varepsilon_{0}$ were $\varepsilon_{g}$ is the gas dielectric constant and $C_{1}$ is now the gas filled value of $C$. For $C_{1} \ell_{0}$ rentain proporlional to $h, \varepsilon_{\ell}$ and $\varepsilon_{g}$ must remain independent of time and fill level.

Capacitance gages have limited application because the liquids in which they are used must leave no residue on the surfaces of the capacitor. Also, the liqujds must have very low electrical conductivity. Liquefied natural gas appears to meet both these requirements.

\subsection{CABLE GAGE}

Cable type level gages consist of a surface sensor of some description suspended on a vertical wire, tape or cable $[14-17,19]$. As the liquid surface and the surface sensor move, the wire, tape or cable is wound on, or unwound from, a storage drum in a gage head to maintain the sensor at the 1iquid surface. The change in length of wire, etc., is measured either by the drum rotation or by a calibrated sprocket located in the gage head. The drum or sprocket drives a counter which gives the level of the liquid. This type of gage is widely used and can be used for most any liquid.

A number of manufacturers build cable operated gages in a range of designs. Some gages, called automatic gages, are mechanical while others are servo driven. In the latter the surface sensor transmits signals enabling the drive motor to maintain the sensor at the liquid surface. 


\section{3 BUBBLER GAGE}

Bubbler gages measure hydrostatic head. The pressure of a noncondensing gas required to displace all the liquid out the open bottom end of a drop tube that extends to the tank bottom is approximately the hydrostatic pressure. Usually, gas is bubbled slowly out the bottom of the tube to insure the liquid level has been forced to the bottom. From the hydrostatic head and the liquid density, the liquid level is calculated.

\section{CAPACITANCE TYPE LEVEL GAGES}

\subsection{GENERAL DESCRIPTION OF GAGES}

A schematic diagram of a capacitance level gage is shown in figure 1 . The gage consists of flanged sections of tube 1 with sections of smaller tube 2 mounted concentrically inside and supported by insulating posts 3 . The inner tube sections are electrically isolated from each other by either a gap or a dielectric plug 4. The outer tube flanges 6 are bolted together so the outer tubes form a single conductor. This outer tube is electrically isolated by the insulator 5 from the tank 8. One lead from the outer tube and leads from each of the center tube sections are brought out of the tank through a seal 7. Often, the center sections of a capacitance gage are connected together electrically within the tank so that leads from only a top, bottom and center section need be brought out along with a lead from the outer tube.

A properly installed gage is supported vertically by the floor of the tank and is supported in the transverse directions but not constrained in the vertical direction at all other points. The segmented design insures that the gage can be handled and installed. It also permits selecting tubes of uniform dimension to minimize variation in the capacitance per unit length. The main purpose of segmenting the gages is to electrically isolate the center segments. Isolating sections allows the gage segments to be electrically switched so only the segment containing the liquid surface and a nearby completely filled segment used for reference are electrically active. Activating only the segment containing the liquid surface and ratioing that capacitance value to the nearby full section capacitance greatly reduces sensitivity of the measurement to changes in the liquid dielectric constant. The effect of uncertainties in the dielectric constant of the gas in the unfilled sections are reduced or eliminated. When a section is filled or emptied, the gage readout automatically switches to the next higher or next lower segment respectively.

The absence of moving parts is an attractive feature of this gage especially for shipboard applications and for tanks subjected to rapid filling and emptying rates. The measurement accuracies estimated are for the tank under static conditions and may not apply while the level is changing.

The two commerically available capacitance level gages are described briefly below.

\subsection{FIRST CAPACITANCE GAGE}

\subsubsection{GAGE DESCRIPTION}

The gage described in this section [18] consists of two thin walled aluminum tubes. The outer tube is about $6 \mathrm{~cm}$ ID and the inner about $4 \mathrm{~cm}$ OD. The inner tube is supported by the outer tube via two orthogonal insulated bolts along diameters. The various centering and supporting insulators are shielded to eliminate leakage currents to the center tube. Shims are placed at the insulator points to compensate for non-linearities introduced by the insulators, so that $\mathrm{dC} / \mathrm{dh}=$ constant where $C$ is the capacitance and $h$ is the height. The flanges are fitted and riveted to the outer tube in a jig. The flange face separations are tested with a gage rod to $\frac{1}{4} \mathrm{~mm}$. The sections can be $3.6 \mathrm{~m}$ or $5 \mathrm{~m}$ in length with one section an odd length as required to bring the assembled gage to the desired height in the tank. Entrance holes for the LNG are provided at the flange collars but nowhere between flanges to avoid weakening the tube. 


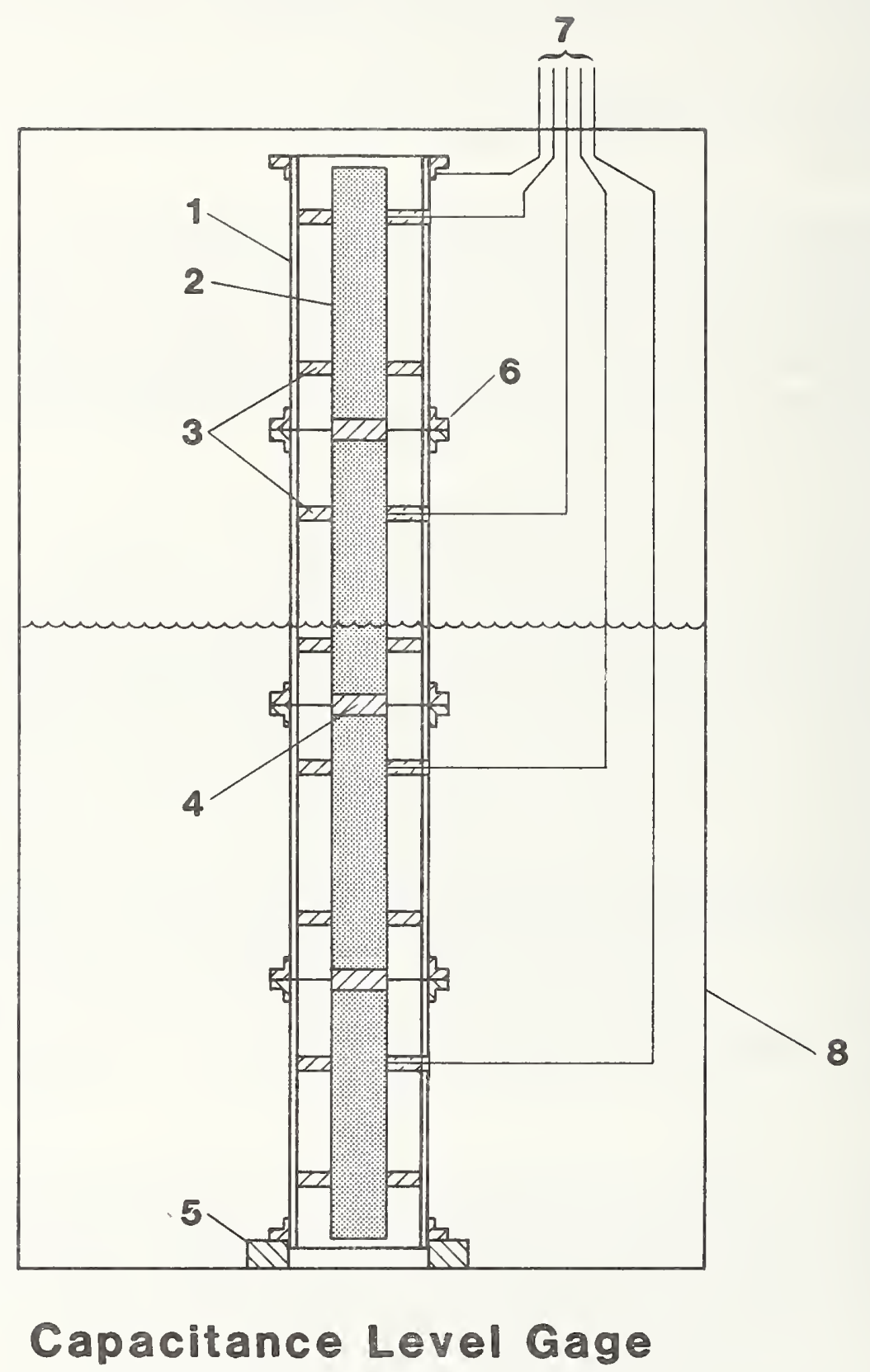

Figure 1. Schematic diagram of a capacitance level gage.

The outer electrode 1 has flanged connections 6 . The inner electrodes 2 are positioned supported by the insulators 3 and separated by gaps or insulating plugs 4 . The insulator 5 supports the gage from the bottom of the tank 8 . The electrical leads 7 are brought out of the tank through gas light seals. 
The gage and associated electronic circuitry is designed so that the full and empty conditions can be simulated at ambient conditions. This provides a method of caljbrating the gage when the tank and gage are at ambient temperature. This calibration procedure cannot be used in an empty cold tank because variations in the gas temperature result in sufficiently large variations in the capacitance of the gage sections. When the tanks are empty and cold, the zero values of each segment can be tested by manually switching in each segment and observing the level reading. If the level reading is not the known height to the bottom of the segment, the segment zero level value is adjusted to read the correct value. When the tank is filled with LNG, and the same segment is switched in, the gain or span of the electronics can be adjusted to give the correct full reading. This is done for each segment.

\subsubsection{MEASUREMENT UNCERTAINTIES}

The lengths of the segments at the LNG boiling temperature of about $-160^{\circ} \mathrm{C}$, are known to

$$
\pm \frac{1}{4} \pm 0.03 \Delta \ell \mathrm{mm}
$$

the second term in this uncertainty arises from the uncertainty of the thermal expansion coefficient of aluminum and $\Delta l$ is the change in length from ambient to the LNG boiling point. The gage sections above the liquid surface can be expected to be at some temperature other than the liquid temperature but these sections do not enter the level measurement. The temperature uncertainty there contributes no error. The uncertainty $\sigma$ of a level measurement when the level reaches a joint between two electrically separated segments $n$ and $n+1$ is

$$
\sigma=\left[0.25 \sqrt{n}+\underset{1}{0.03 \Sigma \Delta e_{n}}\right] \mathrm{mm}
$$

Only the uncertainty of the section length and the uncertainty of the expansion coefficient [21] contribute to the measurement error when the liquid level is located at a joint. This equation assumes that no error is introduced by the readout circuitry.

As the level of the liquid moves above a joint between electrically separated segments, the linearity and resolution of the electrical components must be included in the gage accuracy. Some unpublished tests of gage sections using freon indicate a level measurement uncertainty no larger than $\pm 3 \mathrm{~mm}$ [20]. This error should be maximum when the level is around the mid point of a segment. The non-linearity introduced by the gap between the ends of the center tube segments is small and included in the $\pm 3 \mathrm{~mm}$ according to the manufacturer.

The manufacturer estimates the total uncertainty due to calibration, capacitor dimensions and linearity, and the electronics as $\pm 3.5 \mathrm{~mm}$ for a single section of the gage. The total uncertainty he places at $\pm 7.5 \mathrm{~mm}$. The system measures level with a resolution of $0.1 \mathrm{~mm}$ and displays the measurement to $1 \mathrm{~mm}$.

\subsection{SECOND CAPACITANCE GAGE}

\subsubsection{GAGE DESCRIPTION}

The gage described below consists of a $6.65 \mathrm{~cm}$ diameter ID $5 \mathrm{~mm}$ wall aluminum tube of with a $1.3 \mathrm{~cm}$ diameter aluminum tube down the center. The $1.3 \mathrm{~cm}$ tube is centered by three plastic insulating rods inserted through holes placed $120^{\circ}$ apart around the tube in a plane perpendicular to the tube axis, and clamped against the inner tube by a band around the outside of the outer tube. These support assemblies are placed periodically along the tubes. No shielding of the insulators or compensation for them was found necessary.

The tubes are segmented usually in $5 \mathrm{~m}$ lengths by flanges welded to the outer tube. The inner tube axial spacing is maintained by insulating spacers between adjacent ends. Holes are provided at 
intervals in the outer tube walls to permit entrance of the tank contents. The flanged outer tube is built to a length and measured. The variation in length is estimated to be $\pm 1 \mathrm{~mm}$.

The gage calibration is done when the tank is completely empty and completely full. With the tank empty, the segments are switched in one at a time and the zero reading of each segment is adjusted to the proper level reading. When the tank is filled, each segment is switched in and the span is adjusted to give the proper full reading. A point sensor on the top segment provides an intermediate point to calibrate the top segment.

\subsubsection{MEASUREMENT UNCERTAINTIES}

The uncertainty $\sigma$ of the level at a joint is for this gage is

$$
\sigma=\left[\sqrt{ } \mathrm{n}+0.03 \sum_{1}^{n} \Delta e_{n}\right] \mathrm{mm}
$$

where $\mathrm{n}$ is the number of segments submerged and $\Delta l$, is the thermal contraction of the cooled segments. The level measurement uncertainty increases as the liquid level moves up into a segment. Non-linearity of the gage results from variation in the tube dimensions $(\sim 0.013 \mathrm{~mm}$ on the inner tube $O D$ and $0.0025 \mathrm{~mm}$ on the outer tube ID). The height uncertainty from these variation is $\pm 4 \frac{1}{4}$ $\mathrm{mm}$ but only a maximum of $\pm 3 \mathrm{~mm}$ has been observed according to the manufacturer. The manufacturer estimates that temperature variation in the tank and variation of the electronics contribute errors of $\pm 1.2 \mathrm{~mm}$ and $\pm 5 \mathrm{~mm}$ respectively. The sum of these errors is $9.2 \mathrm{~mm}$ and the rms value is $6 \mathrm{~mm}$. The systematic error from equation (3.2) for $5 \mathrm{~m}$ sections with a $1 \mathrm{~mm}$ length uncertainty is $\pm 5 \mathrm{~mm}$ at the top of a $25 \mathrm{~m}$ high tank which raises the rms uncertainty to about $\pm 8 \mathrm{~mm}$ at the top of the tank.

\subsection{DISCUSSION}

The capacitance level gages of the two manfacturers differ in detail. Fundamentally, they are similar and the experiences and needs of field use have resulted in modifications that have enhanced their similarities.

The uncertainty estimates cited in the manufacturers' literature are $\pm 7.5 \mathrm{~mm}$ and $\pm 10 \mathrm{~mm}$ for the first and second type gages respectively. If the error estimates by the manufacturers for linearity, gas temperature in the unfilled portion, electronics and thermal expansion coefficients of the aluminum tube are correct, then the error estimates by both manufacturers are conservative. Test data taken by one'manufacturer, using freon at ambient temperature to simulate LNG tends to confirm the conservative nature of the estimate since the gage agreed with a ruled standard to \pm 3 $\mathrm{mm}[20]$.

Freon, however, will not behave the same as LNG. The latter can foam, the heavier hydrocarbons might preferentially adhere to the gage surfaces and cause larger level error readings than noted for freon. Variation in both gas and liquid density in the tank can introduce measurement error. Segmenting the gage eliminates any error that otherwise would have been introduced by the completely filled or completely empty segments. The gage accuracy cannot be tested or monitored readily. The full and empty calibration measurements are probably separated by 24 hours at least for transport tanks and perhaps by weeks or months in storage tanks. The top section-full calibration can only be tested by raising the liquid level above the gage either while filling or after filling by pumping liquid from tank to tank unless an intermediate level sensor is provided.

Circulation of the liquid and gases during the filling and emptying of the tanks and ship motion while at sea can be expected to minimize liquid variations. However, special precautions are necessary to prevent density stratification at the very bottom of spherical tanks during filling. Stratification has been observed in spherical tanks especially when top filled. As the tank is cooled to the LNG cargo temperature, methane is flashed off while heavier components collect. Since a very small volume is incorporated in the bottom of a spherical tank, these heavy components can form a layer of sufficient depth to interfere with the automatic switching of the gage to higher segments as the liquid level rises. 
If the gage can be calibrated at ambient temperature, then in ship tanks it could presumably be calibrated once a year during the usual yearly inspection. Shore based storage tank gages, since the tanks may never be warmed to ambient, do not present sufficient opportunities for ambient recalibration.

A possibility of overestimating capacitance gage accuracy exists. To establish accuracy of capacitance gages, the gages should be tested over a period of time in LNG service. This could be done in a special calibration facility or in a storage tank by comparing them to another gage of proven accuracy. Such a gage does not now exist, but a cable compensated gage, if tested for accuracy ( see Appendix A), could be used.

\section{CABLE GAGE TESTS}

\subsection{INTRODUCTION}

Cable gages as presently installed can be subject to large level measurement errors. However, the compensation methods outlined in Appendix A could significantly improve gage accuracy. With compensation, cable gages could meet and probably exceed the estimated accuracy of capacitance level gages. The low cost of a cable gage and the relative ease with which it can be removed and serviced make the cable gage an attractive alternative for the capacitance gage.

The error estimates for cable gage measurements in Appendix $A$ assume that the gage itself contributes a negligible amount to the level measurement error when compared to those introduced by temperature and tank movements. To ascertain that the intrinsic errors of the gage are indeed smal1, the accuracy of four different types of cable gages representing most types commercially available, were tested in an ambient temperature test facility. The facility, the tests and the results are discussed in the remainder of this section.

\subsubsection{GAGE ACCURACY TEST FACILITY}

The accuracy of the gages, essentially the accuracy of the cable position measuring device, was tested in a facility installed in the air shaft of the University of Colorado Physics Building. Access to the shaft permitted testing gage accuracy at six points in a $31 \mathrm{~m}$ height. A schematic of this installation is shown in figure 2. The horizontal cross section of the air shaft is about $1 \mathrm{~m}$ by $3 \frac{1}{2} \mathrm{~m}$. At alternate floor levels, a $3 / 4 \mathrm{~m}$ wide by $23 / 4 \mathrm{~m}$ high ventilation opening covered by a grill work penetrates the narrow side of the shaft. These openings occur on the even numbered floors on the side used for the tests. A $1 \frac{1}{4} \mathrm{~m}$ high frame was clamped in place across each opening supported by the floor. A right triangular plate with its plane vertical was attached to the top end of the frame as shown in figure 2. At the free end of this plate, a piece of aluminum angle was bolted with one flange horizontal and above the triangular plate. This horizontal or reference surface was milled flat. The arm could be rotated about two orthogonal horizontal axes so the milled surface could be leveled.

The reference point at the shaft bottom consisted of two horizontal plates separated by a section of pipe which had been machined square on the ends and clamped between the plates. The top plate served as a reference surface and the lower plate, a base. The cantilevered end of the reference plate was leveled by adjusting leveling bolts at the corners of the triangular base plate.

The reference point on the 10th floor frame was mounted approximately $\frac{1}{2} \mathrm{~m}$ above the floor to provide clearance between the gage heads and the reference surface to accommodate the surface sensors. The gage heads were mounted $1 \frac{1}{4} \mathrm{~m}$ off the floor on two horizontal about $15 \mathrm{~cm}$ ( $6 \mathrm{in}$.) aluminum channels supported on the 10th floor end by the frame supporting the reference point and on the opposite end by a frame hanging from the 11 th floor.

These channels also supported an iron-36\% nickel calibration tape used to measure the separation of the reference surfaces. This tape was suspended from a $U$ shaped frame that could be rolled forward to $\mathrm{place}$ the tape in the notches milled in each of the reference surfaces when measuring their separations. The notches were aligned so the tape hung straight through them. During gage tests, the tape was rolled back out of the way of the gage as shown in figure 2. 


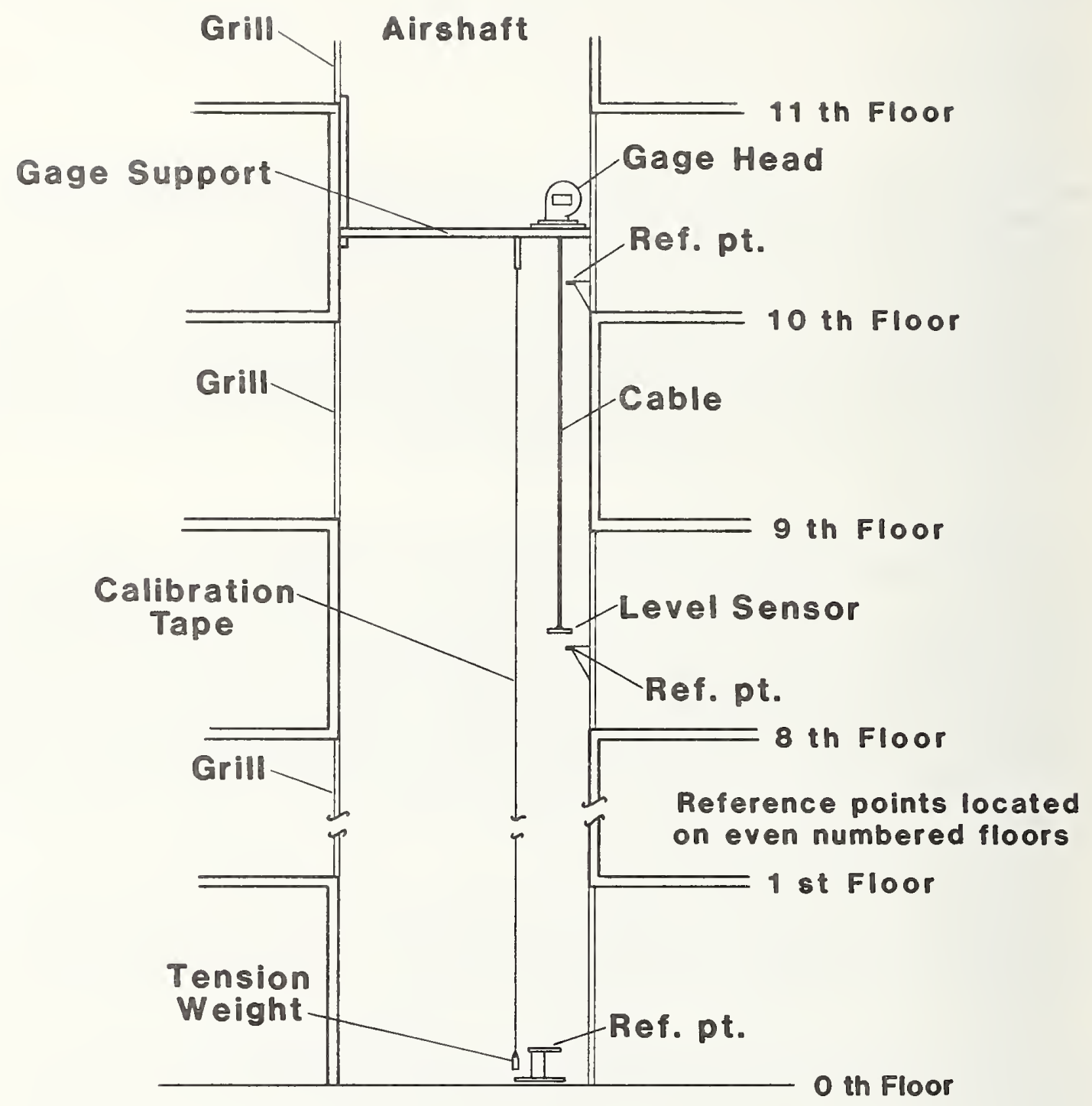

\section{Ambient Calibration Facility}

Figure 2. Ambient calibration facility for cable gages. 
With the calibration tape positioned in the notches and the $5.2 \mathrm{~kg}$ tape tensioning weight in place, the tape was scribed at a level approximately $16 \mathrm{~mm}$ above each reference point by using an $5 / 8$ in. gage block laid on each reference surface as a bottom guide for the scriber. The relative positions of the resulting six scribe marks were measured in the tape calibration facility at Gaithersburg. The calibration certificate for this tape appears in Appendix B.

This tape was used periodically during the tests to remeasure the relative positions of the six reference surfaces. The distance of each scribe line above the reference surface was measured as often as twice a day during tests. A steel scale, calibrated in hundredths of inches was used to make these offset measurements to an estimated precision of about $0.1 \mathrm{~mm}$. The overal1 accuracy of the spacings between levels is estimated at $\pm 0.3 \mathrm{~mm}$. This estimate comes from some photogrammetric calibration accuracy tests in which this tape and similar tapes were used.[22]

The air temperature in the shaft was monitored by liquid in glass thermometers at each level. The temperature varied by as much as $3 \frac{1}{2}{ }^{\circ} \mathrm{C}$ from the top to the bottom of the shaft in early May when the outdoor temperature was generally lower than inside temperatures. The major part of the difference occurred between the 2nd floor and 0th floor (the shaft bottom) where the airshaft is not surrounded by offices. The air temperature at each floor changed less than $1^{\circ} \mathrm{C}$ over the period of a day or over the course of several days. During the summer months, the gradient up the airshaft was generally less than $2^{\circ} \mathrm{C}$ and the bottom level was often as warm as the top. Again temperature changes over the course of a day or days were less than $1^{\circ} \mathrm{C}$. Mainly because the building is air conditioned from May to August the average shaft air temperature only changed from about 22 to about $26^{\circ} \mathrm{C}$ and the total height change in the test area was less than $1 \frac{1}{2} \mathrm{~mm}$ between the zero and 10th floor. Because the shaft height and air temperature changed by such small amounts, reference point positions relative to the calibration tape were measured no more than twice a day during the actual tests.

\subsubsection{HYSTERESIS TEST FACILITY}

Tests using the fixed reference points in the air shaft only emulate a dropping liquid surface and thus did not provide a convenient means of examining gage hysteresis. Consequently, the servo gages were tested for hysteresis on a mill table. The servo gage hysteresis was assumed independent of the gage head elevation as indeed it should be. The error of the fourth cable gage, an automatic gage, is not expected to be independent of position hence the hysteresis of this gage was examined in the air shaft test facility.

To test the servo gages for hysteresis, they were mounted on a tower about $1.5 \mathrm{~m}$ high clamped to the table of a large horizontal mill. The gageheads were offset from the tower on the ends of two approximately $15 \mathrm{~cm}$ (6 in.) channels as shown in figure 3 . A horizontal aluminum plate was rigidly attached to the mill head to provide a movable reference surface in contrast to the air shaft test facility where the reference points were fixed. An electronic machine scale measured the vertical motion of the mill head to $0.1 \mathrm{~mm}$ resolution. The mill head hysteresis and scale accuracy was tested with a dial indicator calibrated in units of 0.001 in. The indicator was mounted on a vertical rod attached to the gage mounting plate. The dial indicator agreed with the machine scale to better than $0.02 \mathrm{~mm}$ and showed no evidence of hysteresis in the mill head. The dial indicator was compared to some gage blocks with which it agreed to $\pm .01 \mathrm{~mm}$.

The hysteresis of the gages using buoyancy change to monitor liquid surface position was measured both against a solid surface and a liquid surface. The liquid surface was provided by water in a $30.5 \mathrm{~cm}$ diameter shallow pan. If the measured hysteresis differs between water and a solid surface, the hysteresis at an LNG surface can be inferred. A gage using thermal surface sensors required a liquid nitrogen surface to properly test it. The shallow pan was replaced by a $20 \mathrm{~cm}$ diameter $90 \mathrm{~cm}$ deep nitrogen dewar.

The tests were done by raising and lowering the mill head, generally in millimeter steps and recording the gage head and mill head height readings. 


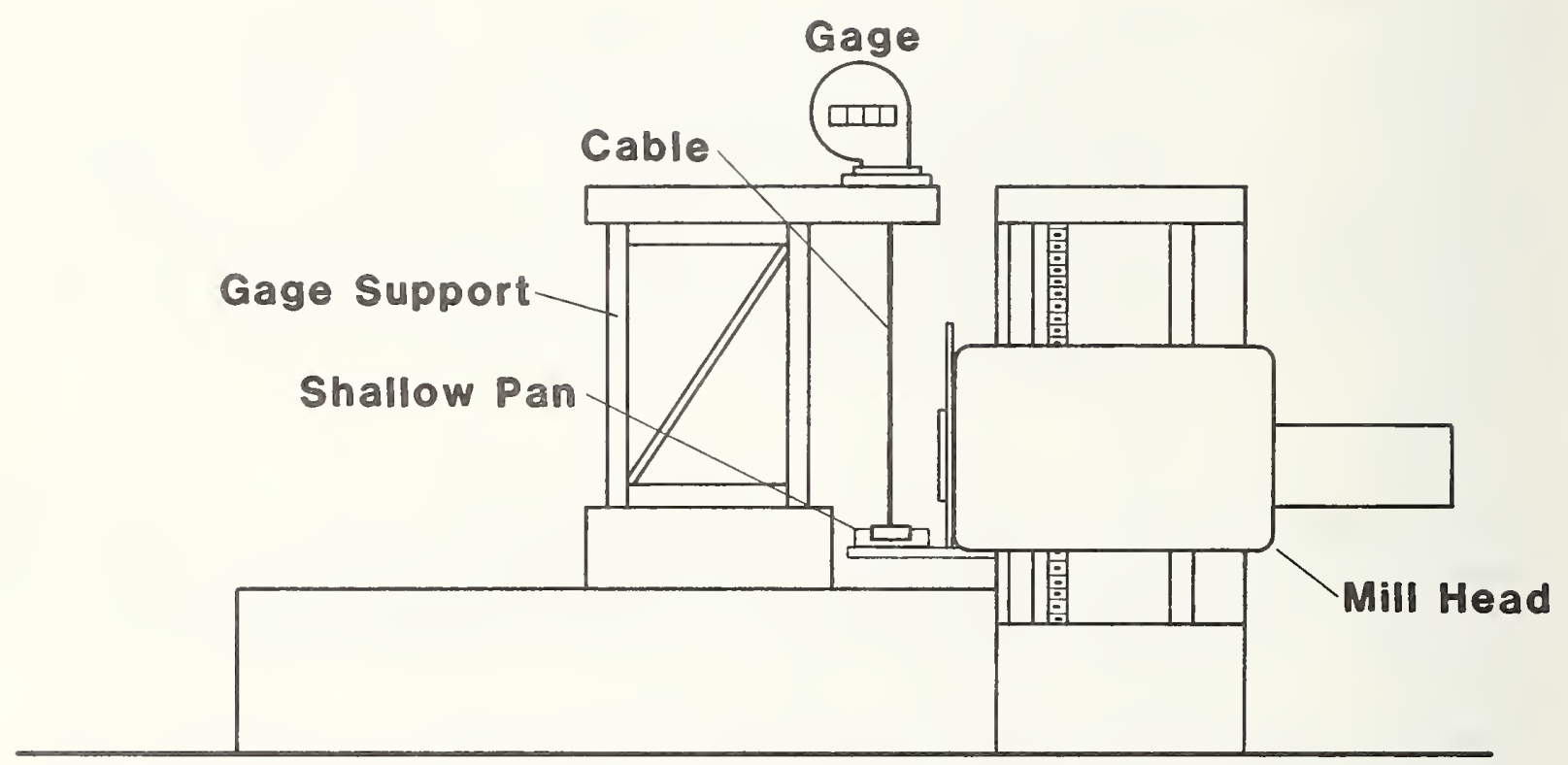

Hysteresis Test Facility

Figure 3. Hysteresis test facility for cable gages. 


\section{2 FIRST CABLE GAGE, SERVO}

\subsubsection{GAGE DESCRIPTION}

The servo gage described in this section uses a displacer suspended on a wire to detect the liquid surface. The wire winds in a spiral slot on a precisely machined drum [19]. The drum is connected through a magnetic coupling to a torque sensing device. When the liquid level falls away from the displacer, the torque increases, and a switch contact closes in the torque sensor. A motor, via a worm and gear, drives the displacer down until it contacts the liquid. There the torque decreases which opens the switch and stops the drive motor. Conversely, if the level rises, the torque falls too low and the opposite switch closes in the torque sensor causing the drive motor to lift the displacer back to the liquid surface. The torque sensor causes the drive motor to position the displacer so the torque is neither high nor low enough to close either switch. A counter is attached to the motor shaft and geared so the count is equal to the height in meters for the unit tested. The shaft also drives switches that control a stepping motor connected to a similar counter at a remote site. The counters have a $\frac{1}{2} \mathrm{~mm}$ resolution and were read to $0.1 \mathrm{~mm}$.

For the tests performed the displacer was sometimes replaced by a brass weight equal to the displacer weight of $223 \mathrm{gm}$. The bottom of the weight was machined flat so it would rest in a reproducible fashion on the reference surfaces. No compliance was introduced between the weight and reference point to simulate a displacer in liquid since compliance already exists in the magnetic coupling within the gage.

\subsubsection{ACCURACY TESTS}

The accuracy tests took place over a span of 6 days with measurements made on the first two and last two days. The gage readings at the reference points on the first measurements down the shaft disagree with all succeeding values by about $3 \mathrm{~mm}$. The later readings were smaller. The difference probably resulted from the wire crossing the ridge between channels on the drum somewhere between the 2 nd and 0 th floor. This $3 \mathrm{~mm}$ decrease in reading was observed at one reference point during all the succeeding measurements and that one was eliminated by dropping the level sensor (the brass weight on the end of the wire) to the next reference point down and raising it again. Probably, the wire crossed over a ridge again when it was pushed to one side to allow the weight to clear a reference arm. The data point was not used in the analysis.

During the tests the displacer weight was raised and allowed to settle again from 5 to 8 times on each reference surface before moving on the next. The average of each set of readings is shown in table 1a. The total scatter of these repeated readings was $\pm 0.1 \mathrm{~mm}$. The gage readings were not adjusted to zero at any reference point. The table is sectioned to show the day the data were taken and the arrow shows whether the sensor was being raised or lowered.

During the period of time these tests were done, some of the reference level positions were measured by the calibration tape 7 times. Four of those times, all the reference level positions were measured. The measured offsets, after adjusting to the average value since the vertical position of the tape can vary, had a spread generally less than $0.1 \mathrm{~mm}$ with the largest being $0.15 \mathrm{~mm}$. Since this spread is within the estimated resolution of a single reading of position relative to a tape scribe mark $( \pm 0.2 \mathrm{~mm})$, no corrections for changes of reference point separations due to building temperature changes were necessary.

Since the spread of the averaged readings for each measurement at a reference level does not exceed $0.3 \mathrm{~mm}$, the averaged values for each measurement at a level were averaged and compared to the calibration tape measurements of level position. In table $1 \mathrm{~b}$ the measurements by the calibration tape and the level gage are converted to the distances from the 10th floor reference surface to each of the others. The spacings given by the level gage are larger but only by $0.8 \mathrm{~mm}$ at the most. The errors suggest a small non-linearity but only two of them exceed the scatter of the data. The results shown in table 1 are from the direct reading dial. The data from the remote readout unit averaged in the same way gave precisely the same values for the reference level separations. 


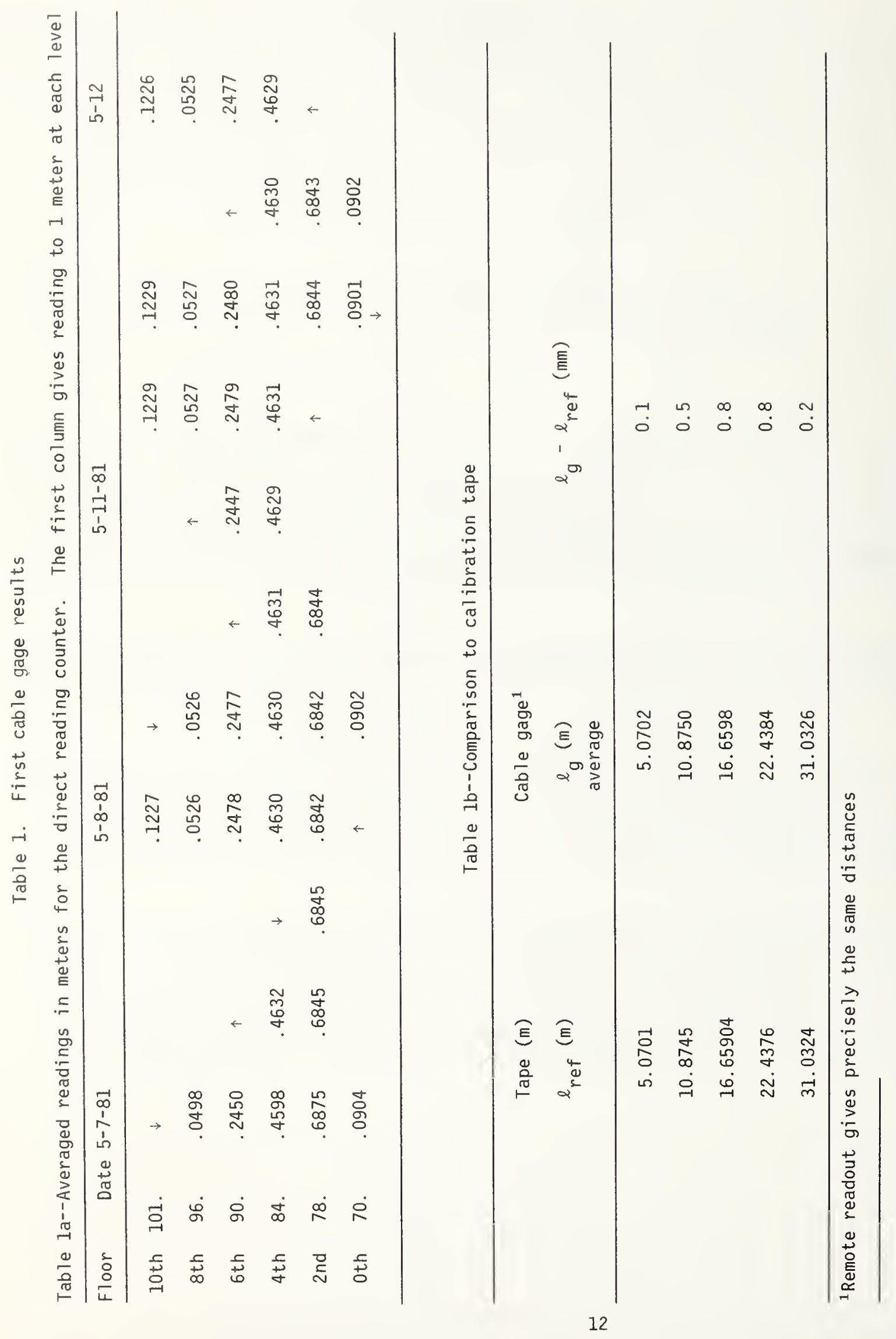


The manufacturer's specifications call for the gage error $\Delta L$ to be

$$
\begin{array}{ll}
\Delta \mathrm{L}<(0.5+0.035 \mathrm{~L}) \mathrm{mm} & \text { "fine precision" } \\
\Delta \mathrm{L} \overline{<}(0.5+0.13 \mathrm{~L}) \mathrm{mm} & \text { "commercial precision" }
\end{array}
$$

where $\mathrm{L}=$ the level in meters, and for infinite density liquid which the reference surfaces simulate. The gage tested was "commercial precision." At a level of $31 \mathrm{~m}$ the allowable $\Delta \mathrm{L}$ values are $\pm 1.6 \mathrm{~mm}$ and $\pm 4.6 \mathrm{~mm}$ for "fine" and "commercial precision," respectively. At $16.66 \mathrm{~mm}$, where the measured difference was maximum, which was $0.8 \mathrm{~mm}$, the error permitted is $1.1 \mathrm{~mm}$ for the "fine precision" gage. Thus, this unit easily exceeds the requirements for "fine precision" at ambient conditions. The scatter of the data, only $0.3 \mathrm{~mm}$ total spread at each level, suggests that a non-linear correction could be applied to make the gage accuracy even greater.

The average air temperature in the shaft decreased by about $1^{\circ} \mathrm{C}$ over the course of the tests. The temperatures in the air shaft decreased monotonically $3 \frac{1}{2}{ }^{\circ} \mathrm{C}$ from the top to the bottom of the shaft. The approximate shrinkage of $31 \mathrm{~m}$ of stainless steel wire for a $1^{\circ} \mathrm{C}$ temperature drop is $0.5 \mathrm{~mm}$. A $\frac{1}{2} \mathrm{~mm}$ change could be resolved. No change of that magnitude is evident in the results.

\subsubsection{HYSTERESIS TESTS}

The gage was tested for hysteresis on the horizontal mill first by using the brass weight against the flat table. The table was moved up and down between $+1,0$, and $-1 \mathrm{~mm}$ for five complete cycles. The five readings at each level generally showed a spread of 0.2 to $0.3 \mathrm{~mm}$ total. The averaged value of level reading for decreasing levels were $0.1 \mathrm{~mm}$ higher than the average values for increasing levels at the same mill head position and for both the local and remote readout. This indicated hysteresis is well within the scatter of the individual measurements.

When the reference surface was water, the direct readout suggested 0.1 to $0.2 \mathrm{~mm}$ hysteresis while the remote readout suggested 0.2 to $0.3 \mathrm{~mm}$. The displacer sensed a water surface that had a crosssectional area about 8 times larger than the float so the water height correction between the extremes of the displacer position relative to the surface is $0.04 \mathrm{~mm}$. Hysteresis to a liqueified gas surface could be expected to double the hysteresis added by water which could be the difference between the water and solid surface hysteresis, $0.2 \mathrm{~mm}-0.1 \mathrm{~mm}=0.1 \mathrm{~mm}$, doubled plus $0.1 \mathrm{~mm}$ or $0.3 \mathrm{~mm}$ for the direct readout. The above estimates of hysteresis are tenuous because the magnitudes estimated are smaller than the scatter of the individual measurements at each level. Therefore, to within the measurement precision, hysteresis is not detectable. Some additional level measurement error results because the wire weight adds to the displacer weight as the level drops. The wire weighs $0.15 \mathrm{gm}$ per meter which is $4.5 \mathrm{gm}$ when extended $31 \mathrm{~m}$. The displacer is $14 \mathrm{~cm}$ diameter so that in LNG at $500 \mathrm{~kg} / \mathrm{m}^{3}$, the displacer can be expected to ride about $0.6 \mathrm{~mm}$ lower at $30 \mathrm{~m}$ depth than at $0 \mathrm{~m}$ depth. This error is proportional to level and if more precise measurements are desired, height corrections for the wire weight can easily be made.

\subsection{SECOND CABLE GAGE, SERVO}

\subsubsection{GAGE DESCRIPTION}

The servo gage described in this section suspends the surface sensor on a stainless steel tape. The tape is actually two side by side strips of stainless steel electrically insulated from the environment and each other by a plastic coating. The level sensor is a $10 \mathrm{~cm}$ diameter foam float free to move over a range of about $1 \mathrm{~cm}$ with respect to the sensing head. A coil in the sensing head, driven by an $A C$ voltage supplied from the gage head through the stainless steel tapes, senses the position of the some magnetic material attached to the float. A servo motor is controlled by the signal from the sensing head and adjusts the position of the head until a null position is achieved. The servo motor drives the tape storage drum. The tape passes over a sprocket whee] whose teeth engage in perforations in the wider of the two stainless steel strips then down to the sensing head. The sprocket wheel drives a mechanical counter and can also drive a transmitter to a remote readout. The least count on the counter drum corresponds to $1 \mathrm{~mm}$. The $1 \mathrm{~mm}$ lines are about $1.5 \mathrm{~mm}$ apart permitting the counter position to be estimated to $0.1 \mathrm{~mm}$. Because the storage drum diameter increases as the tape is wound, the driving speed was greater than $0.6 \mathrm{~m} / \mathrm{min}$. near full 
and about $0.4 \mathrm{~m} / \mathrm{min}$. near empty. The control circuit drives at a rate proportional to offset near the null point making overshoot almost undetectable as the sensing head approaches the rest position.

\subsubsection{ACCURACY TESTS}

The gage accuracy was tested relative to the reference levels during three round trips up and down the air shaft. The gage head approaches the reference levels always from above so the float could rest on the reference surface. The bottom reference point was raised by a gage block approximately $10 \mathrm{~cm}$ ( 4 inches) because the tape was not long enough by a few $\mathrm{cm}$ to reach the bottom reference surface.

The averaged value for the level gage reading at each reference level for all the measurements at each level is shown in table $2 a$. The total spread of the data at each level is $0.5 \mathrm{~mm}$ or less. This precision approaches the resolution of the gage scale. The location of the dial reference causes some reduction of reading precision because of parallax.

Table $2 \mathrm{~b}$ and figure 4 show the difference between the reference surface spacings determined by calibration tape and from the gage readings.

The bars on the averaged data points in figure 4 show the total spread of the data averaged at that point. The gage reads a value for the reference point readings $6 \mathrm{~mm}$ too small corresponding to a liquid level $6 \mathrm{~mm}$ high at the $31 \mathrm{~m}$ level. The average differences for the intermediate levels fit a linear correction to $\pm 0.2 \mathrm{~mm}$, which is well within the limits of the combined precision of the gage readability and the calibration tape measurement. A correction factor can readily be applied to the gage readings for high accuracy measurement. For this gage $1.00020 \times$ (gage reading) corrects the readings to the calibration tape -5cale. The manufacturer has found half this offset in one tape calibration and suspects additional offset might be there. At this writing, he is endeavoring to eliminate this offset.

The effect of cryogenic temperatures on the plastic coated tape was given cursory examination by cooling a section of the tape in liquid nitrogen. No reduction in the tape flexibility was evident in the section at liquid nitrogen temperature nor was there any evident effects from differential contraction.

\subsection{HYSTERESIS TESTS}

The hysteresis tests on this gage were done first with the float in the sensor head resting on the shelf attached to the mill head. Three complete cycles (moving the table zero to $+1 \mathrm{~mm}$ to zero to - $1 \mathrm{~mm}$ to zero is one cycle) and a cycle to $\pm 0.2 \mathrm{~mm}$ resulted in no measurable difference between the gage and the mill head reading.

Next, the float was tested with a water surface in a $30.4 \mathrm{~cm}$ diameter pan. Over the course of three cycles through 1,0 and $-1 \mathrm{~mm}$, the maximum hysteresis was again less than $0.1 \mathrm{~mm}$, i.e., no hysteresis was detected to the readability of the gage. During these water tests, the float settled 2 to $3 \mathrm{~mm}$ into the liquid. If the liquid were $500 \mathrm{~kg} / \mathrm{m}^{3}$ natural gas, the float would be expected to settle 4 to $6 \mathrm{~mm}$ into the liquid. If the LNG density changed by $10 \%$ the gage would change by $0.6 \mathrm{~mm}$ at the same liquid level. If higher precision is desired a correction can be introduced by measuring the liquid density and calculating the relative shift resulting from density change.

\subsection{THIRD CABLE GAGE, SERVO}

\subsubsection{GAGE DESCRIPTION}

The cable gage described in this section uses a hollow cable to connect the surface sensor to the gage head [17]. A number of electrical leads pass through this hollow cable. The leads connect a densimeter, a thermometer and the surface detectors in the surface sensor to their respective electronics in the gage head. The two surface detectors are thermal devices and cause the surface sensor to be driven to a position such that the lower detector is immersed, and the upper detector is above the liquid surface. The surface detectors are separated vertically by about $3 \mathrm{~mm}$. 
Table 2. Second cable gage results

Table 2a--Averaged reading and total spread

\begin{tabular}{ccc}
\hline Floor level & $\begin{array}{c}\text { Average gage } \\
\text { reading }(\mathrm{m})\end{array}$ & $\begin{array}{c}\text { Total } \\
\text { spread (mm) }\end{array}$ \\
\hline 10th & 79.3940 & \pm 0.1 \\
8th & 74.3250 & +0.1 \\
& & -0.2 \\
6th & 68.5210 & +0.2 \\
& & -0.0 \\
4th & 62.7376 & +0.3 \\
& & -0.2 \\
2nd & 56.9602 & -0.3 \\
& & +0.2 \\
0th & 48.4678 & -0.3 \\
\end{tabular}

Note: Averages of 14 to 19 readings over 2 days. Each level approached three times each going up and going down.

Table 2b--Comparison to calibration tape

\begin{tabular}{cccc}
\hline $\begin{array}{c}\text { Distance below 10th } \\
\text { floor reference }\end{array}$ & $\begin{array}{c}\text { Gage } \\
\ell_{\mathrm{g}}(\mathrm{m}) \\
\text { average }\end{array}$ & $\begin{array}{c}\text { Tape } \\
\ell_{\text {ref }}(\mathrm{m})\end{array}$ & $\begin{array}{c}\ell_{\mathrm{g}}-\ell_{\text {ref }} \\
(\mathrm{mm})\end{array}$ \\
\hline 10th & 0 & 0 & 0 \\
8 th & 5.9690 & 5.0701 & 1.1 \\
6 th & 10.8730 & 10.8748 & -1.8 \\
4 th & 16.6564 & 16.6594 & -3.0 \\
2 nd & 22.4338 & 22.4382 & -4.4 \\
0 th & 30.9262 & 30.9322 & -6.0 \\
\hline
\end{tabular}




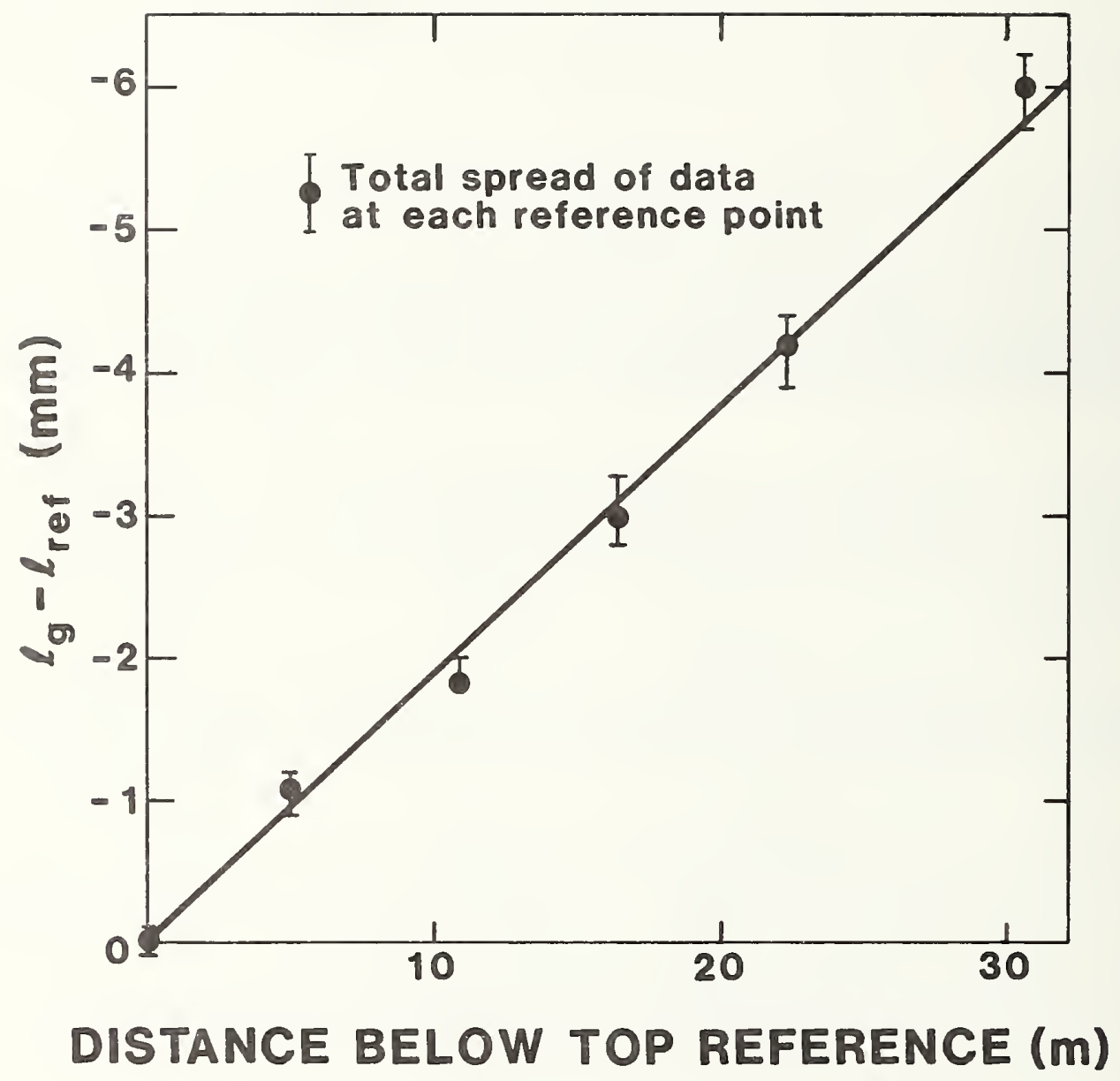

Figure 4. Results of the accuracy test of the second cable gage. 
The cable consists of a flat wire wound in a tight coil around which one layer of 30 to 40 fine wires is twisted in a spiral of about one turn in $5 \frac{1}{2} \mathrm{~cm}$. Around the outside, a single much heavier wire is spiraled at a pitch of about one turn per $4 \mathrm{~mm}$. A notched drive wheel meshes with this spiral wire and drives the sensor up and down. A stepping motor powers the drive wheel and the sensor position is monitored by counting the pulses to the stepping motor. The instrument is provided with a calibration by setting an appropriate number into some switches. This number determines the advance of the counter per pulse to the stepping motor. The excess cable is stored on a spring-motor-driven drum in the drive head. The readout resolution of $1 \mathrm{~mm}$ cannot be interpolated since this is the least count of an electronic counter.

This gage has a unique feature. Rather than using a point on the tank roof for a reference point for setting the gage zero, this gage can be rezeroed by allowing the surface sensor to come to rest on the tank bottom. The ensuing reduction of weight trips a switch in the gage head that resets the level readout to a zero value. Then the surface sensor is returned to the liquid surface. This method of determining the gage zero removes errors introduced by temperature distributions in the tank walls and ullage provided the tank and environment are at steady state conditions (see Appendix A for details).

\subsubsection{ACCURACY TESTS}

This device senses level by means of temperature probes and always hangs with full weight on the cable other than for a small buoyancy effect change. Thus, the level sensor could not be lowered against a reference surface to measure its position because the cable would slack. Instead the sensor was brought to a point where the counter read a fixed level, around 13 to $15 \mathrm{~cm}$ above each reference surface, and the separation from the reference was measured with a dial indicator. The dial gage reading remained $15.57 \mathrm{~mm}(0.613 \pm .001 ")$ when placed between the two plates separated by $127.0 \mathrm{~mm}$ by a 5 -inch gage block throughout the test of this gage. The dial gage read so that the spacing between the sensor bottom and the reference point was

$$
S=(5.000-r+0.613)(0.0254) m
$$

where $r$ is the dial gage reading in inches. The spacing $S$ was subtracted from the gage reading $x$ to give the reference point position in the gage coordinates. The reference position $p$ is then

$$
p=x-(5-r+0.613)(0.0254) m
$$

The spacing of the othen reference points from the bottom reference point is

$$
\mathrm{p}-\mathrm{p}_{0} \doteq \mathrm{x}-\mathrm{x}_{0}+\left(\mathrm{r}-\mathrm{r}_{0}\right)(0.0254)=\Delta \mathrm{p}
$$

where $p_{0}, x_{0}$, and $r_{0}$ are the zero floor reference level values. The results have been examined by plotting $\Delta \mathrm{p}_{\text {gage }}-\Delta \mathrm{p}_{\text {actual }}^{0}$ as a function of $\mathrm{p}^{-} \mathrm{p}_{\mathrm{o}}$.

Initially this gage was tested without the fixed guide wires since the gage design did not require them if no currents were present that could deflect the level sensor and cable from vertical. However, during these initial tests, the level sensor rotated around the axis of the cable as much as 5 turns in the course of traversing the height of the shaft. The measurements often did not repeat by a few millimeters when the sensor was returned to a reference point and the gage reading was non-linear by about $1 \mathrm{~cm}$ over the height of the shaft.

A second set of tests was conducted with guide wires installed to constrain the sensor from rotating. In practice, most gages are installed with these guide wires.

The addition of the guide cables removed the non-repeatability observed in the first tests and significantly reduced the non-linearity. The results are shown in table 3 and figure 5 .

As can be seen in figure 5 , the scatter of the level readings are almost all within the resolution of the gage, estimated below to be $\pm 1.0 \mathrm{~mm}$. The scatter is shown by the brackets at each reference levei. The estimated uncertainty of the dial indicator measurement, $\pm 0.2 \mathrm{~mm}$, has not 
Table 3. Third cable gage results

Table 3a--Differences from reference level positions

\begin{tabular}{|c|c|c|c|c|c|c|}
\hline \multirow{2}{*}{$\begin{array}{c}\text { Reference level } \\
\text { Floor } \\
\text { oth }\end{array}$} & \multicolumn{6}{|c|}{$\begin{array}{l}\text { Deviation of the gage reading from reference value } \\
\qquad l_{g}-l_{\text {ref }}\end{array}$} \\
\hline & $\downarrow 0$ & $\uparrow+1.3$ & $\downarrow 0$ & $\uparrow-0.1$ & $\downarrow 0$ & $\uparrow 0$ \\
\hline $2 n d$ & -6.3 & -6.7 & 6.1 & -6.5 & -6.6 & -6.7 \\
\hline 4 th & -7.0 & -7.2 & -7.1 & -8.0 & -6.9 & -7.4 \\
\hline 6 th & -7.2 & -7.7 & -7.5 & -7.6 & -7.8 & -7.7 \\
\hline 8 th & -4.4 & -6.0 & -5.1 & -5.7 & -4.6 & -5.2 \\
\hline 10 th & -2.9 & & -3.5 & & $-3.6^{1}$ & \\
\hline
\end{tabular}

${ }^{1}$ Changed $r_{0}$ here because gage sensor stalled against top reference point.

Table 3bComparisons of averaged gage separations to calibration tape values

\begin{tabular}{ccc}
$\begin{array}{c}\ell_{\text {ref }} \\
\text { Calibration } \\
\text { tape }(\mathrm{m})\end{array}$ & $\begin{array}{c}\ell_{\mathrm{g}} \\
\text { Gaverage } \\
(\mathrm{m})\end{array}$ & $\begin{array}{c}\ell_{\mathrm{g}}-\ell_{\text {ref }} \\
(\mathrm{mm})\end{array}$ \\
\hline 0 & -0.6 & -0.6 \\
8.5869 & 8.5803 & -6.6 \\
14.3653 & 14.3580 & -7.3 \\
20.1500 & 20.1424 & -7.6 \\
25.9544 & 25.9492 & -5.2 \\
31.0242 & 31.0209 & -3.3 \\
\hline
\end{tabular}




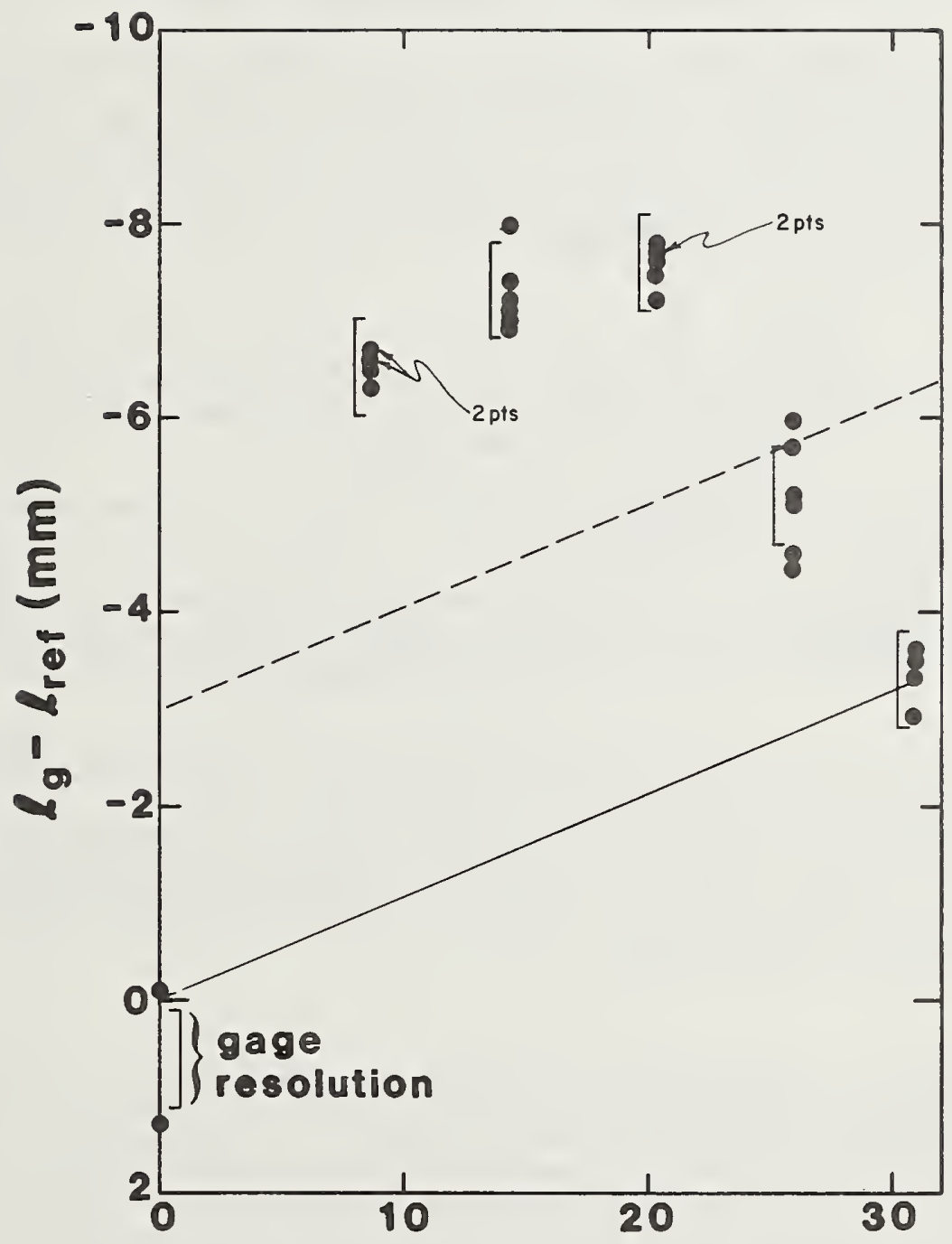

\section{DISTANCE FROM BOTTOM REFERENCE (m)}

Figure 5. Results of the accuracy tests of the third cable gage. 
been included in the resolution. Only two repeat values of the zero reading at the shaft bottom were obtained rather than three because the sensor momentarily caught on the 10th floor reference arm as it approached the top in the last measurement. This shifts the zero because the stepping motor stalls but the counter continues counting steps. The going down zero was used for the measurements back down the shaft.

As the dotted line in figure 5 shows, the gage calibration needs to be adjusted to count $3 \mathrm{~mm}$ higher over the $31 \mathrm{~m}$ between top and bottom. With that adjustment and a shift of the zero reading to read $3 \mathrm{~mm}$ high, the gage accuracy would 1 ie within $\pm 3 \mathrm{~mm}$ of the true value over the range. If higher accuracy is needed, a curve may be fit through the data in figure 5 and a correction applied to the gage readings. This would yield levels accurate to about $\pm 1 \mathrm{~mm}$.

The non-linearity shown in figure 5 probably originates with the cable. Very slight differences in the spacing of spirals of the wrapping can accumulate to measurable errors. This variation could be introduced during the manufacture of the cable. Stresses in the cable introduced during the manufacture probably cause the center of the cable to twist relative to the ends. Because of the spiral wrap, this adds turns of the wrap between the center and one end while reducing by the same amount the number of wraps between the center and opposite end. The deviation from linearity shown in figure 6 would result if a $1 \frac{1}{2}$ turn twist were present in the center of the cable since the pitch of the wrap is about $4 \mathrm{~mm}$ per turn.

Before pulling the sensor up the last time, the cable was constrained from rotating and the center twisted counter clockwise 15 turns then released. This caused a slight change in the difference readings at the 8 th and 10 th floors. Any difference was less than $2 \mathrm{~mm}$. This implies that the cable is quite stable with respect to twist at ambient temperature.

Because of the non-linearity of the instrument, the gage should be calibrated using several rather than two reference levels for best accuracy.

The gage is driven by a stepping motor and the calibration of $0.26229 \mathrm{~mm} / \mathrm{step}$ is added to a register recording $0.00001 \mathrm{~mm}$ in the last place. The reading is displayed to the nearest millimeter so the readout uncertainty is $\pm 1 \mathrm{~mm}$. The uncertainty associated with the difference between two readings is also $\pm 1 \mathrm{~mm}$.

The mechanism that zeros the counter when the sensor contacts the tank bottom is a weight-actuated switch that trips when some of the sensor load is taken up by the tank floor. During the tests without guide wires, the gage was allowed to zero several times on the bottom reference then raised to a height reading of 130 ' mm above the bottom reference and the height measured with the dial indicator. The results are shown in table 4. The total spread of the data is less than $1 \mathrm{~mm}$. This is within the resolution of the gage and suggests that the zeroing process does not add a significant error to the position measurement.

\subsection{HYSTERESIS TESTS}

This gage thermally senses the liquid surface. To do the hysteresis tests, a $90 \mathrm{~cm}$ deep by $20 \mathrm{~cm}$ diameter dewar containing liquid nitrogen $\left(L_{2}\right)$ was placed on the shelf on the milling machine head. A $16 \frac{1}{2} \mathrm{~cm}$ diameter copper can was placed inside the dewar. A $\frac{1}{2} \mathrm{~cm}$ diameter hole was drilled through the wall of this can so that when the level sensors were lowered to the height of the hole, the bottom of the sensing head was stil1 about $8 \mathrm{~cm}$ above the bottom of the copper can.

The copper can was filled with $L N_{2}$ to the level of the hole. The annular gap was also filled but to a lesser height. The level in the inner can could be maintained to the level of the hole by adding small amounts of $\mathrm{LN}_{2}$ and allowing the excess to run through the hole into the annulus. All of the boiling caused by heat leak takes place in the annular space. No boiling was noted in the inner can.

Hysteresis was first examined by varying the mil1 head position between $+5 \mathrm{~mm}$ to $-5 \mathrm{~mm}$ in $1 \mathrm{~mm}$ steps. The gage drive was set to automatic, the mode that causes the sensor to follow the liquid surface. The results of one such measurement is shown in figure 6 . The hysteresis is about \pm 3 $\mathrm{mm}$. The gage would start to change between the $\mathrm{mm}$ steps. This is indicated by the curved dotted 


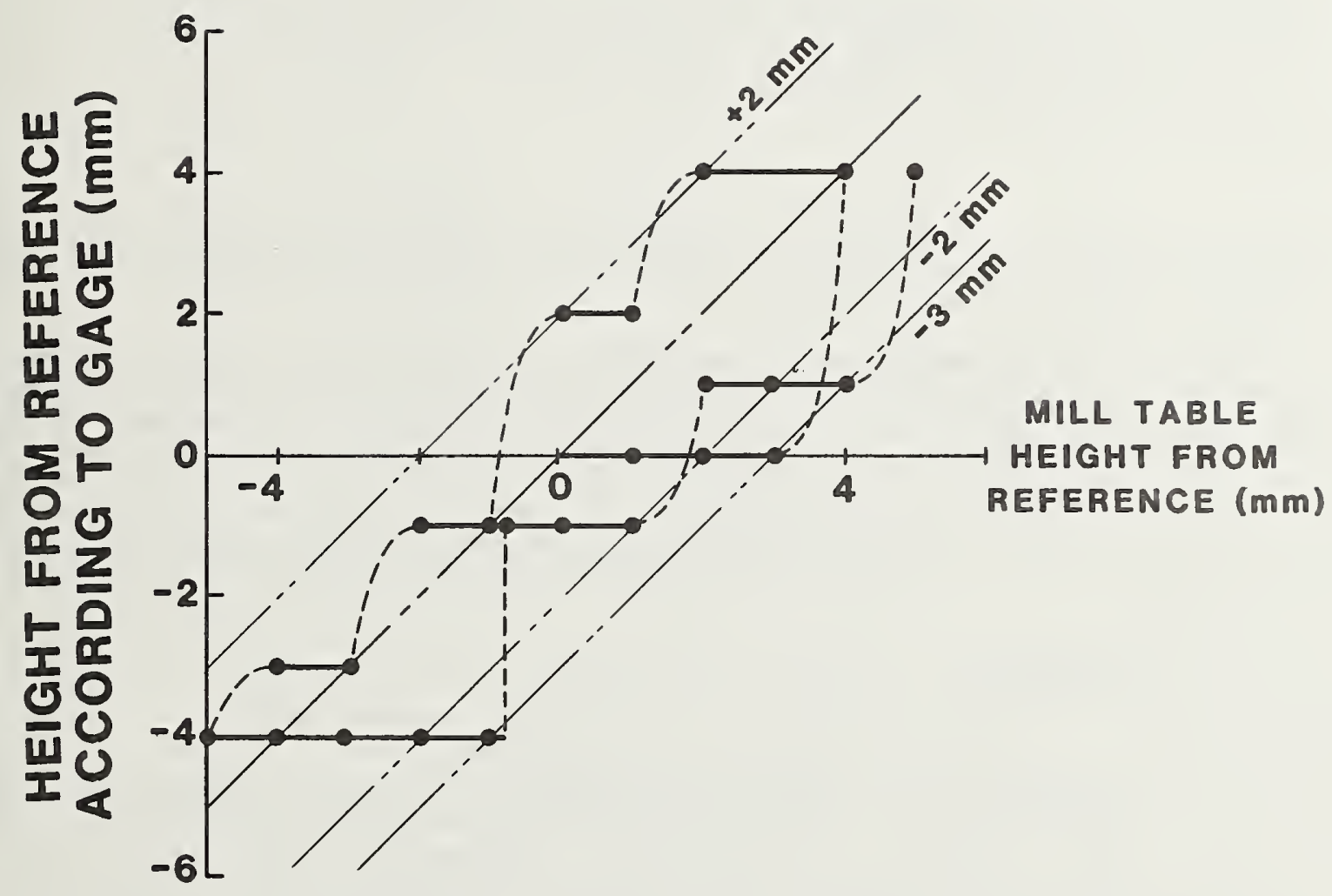

Figure 6. Results of a hysteresis test on the third cable gage. 
Table 4--Rezero accuracy of the third cable gage

\begin{tabular}{ll}
\hline Rezero date & Dial gage $^{*}$ \\
\hline $7-8-81$ & $130.5 \mathrm{~mm}$ \\
$7-14-81$ & $130.5 \mathrm{~mm}$ \\
$7-15-81$ & $131.1 \mathrm{~mm}$ \\
$7-24-81$ & $130.5 \mathrm{~mm}$ \\
& $130.5 \mathrm{~mm}$ \\
\hline
\end{tabular}

* Reading with sensing head raised to a reading of $13.0 \mathrm{~cm}$ above zero value.

Note: The average height measured by the dial indicator is $130.6 \mathrm{~mm}$.

The total spread of the data is $0.8 \mathrm{~mm}$.

sections of the curve. If instead the table is stopped when the gage started to change, then the table position and new gage reading recorded, the hysteresis was similar in magnitude. The manufacturer's estimate of the hysteresis is $3 \mathrm{~mm}$.

The gage was also tested in the manual mode by first driving the gage sensor up about $1 \mathrm{~cm}$ then switching to automatic and allowing the gage to set itself at the liquid level. Next, the gage head was driven down and allowed to return to surface automatically again. This was done at other positive and negative table positions. The gage returns to the same position to within about $1 \mathrm{~mm}$ regardless of whether the gage sensor was driven up or down. This was also true at points offset from the table zero position. Some change of the $\mathrm{LN}_{2}$ level and perhaps rotation of the sensor head, since no guide wires were used, caused shifts during the course of these measurements but the results suggest that the level uncertainty resulting from hysteresis could be reduced to $\pm 1 \mathrm{~mm}$ by following this procedure.

\subsection{FOURTH CABLE GAGE, AUTOMATIC}

\subsubsection{GAGE DESCRIPTION}

Historically, the earliest gages of the cable type were the automatic gages. Automatic gages are completely mechanical devices unless fitted with a remote display unit [15]. They are easy to make intrinsically safe, often a requirement for shipboard use. The gage tested here is built especially for shipboard use on cryogenic liquids and is a roof mounted gage. A foam float is connected to the gage head via a perforated stainless steel tape. In the gage head, the tape passes over a sprocket wheel which drives a counter and is wound on a spring motor driven storage drum. The spring motor winds the tape on the drum as a rising liquid level raises the float but is sufficiently weak that the weight of the float unwinds the tape as the level falls.

The gage tested is the automatic gage widely used in large LNG tanks. In marine service, the float is stored at the topmost position when the ship is in motion to prevent damage to the gage. A crank on the gage head engages the storage drum permitting the float to be raised. The float is held at the gage head by a latch mechanism.

The direct readout dial is in meters with graduations of $1 \mathrm{~mm}$. The $\mathrm{mm}$ marks have about a $1 \mathrm{~mm}$ spacing and the reading was estimated to $0.1 \mathrm{~mm}$. This unit measures ullage height rather than liquid height. The zero of the gage was not changed from the zero setting when received. 


\subsubsection{ACCURACY TESTS TO A SOLID SURFACE}

The gage tests in the air shaft facility were done first by allowing the float to come to rest on each reference surface. An aluminum plate was attached to the bottom of the foam float to give it a more durable and reproducible surface. One set of gage readings at the reference levels were taken going down and back up the shaft. These results are shown in table 5 . The gage and calibration tape distances agreed to $\pm 0.8 \mathrm{~mm}$.

Table 5--Comparison of calibration tape and fourth cable gage against a solid reference surface

\begin{tabular}{|c|c|c|c|c|c|}
\hline \multirow[b]{2}{*}{ Floor } & \multirow{2}{*}{$\begin{array}{c}\text { Calibration } \\
\text { Tape }\end{array}$} & \multicolumn{2}{|c|}{ Spacings (m) } & \multicolumn{2}{|c|}{$\ell_{g}-\ell_{\text {ref }}(\mathrm{mm})$} \\
\hline & & $\overline{\text { Gage (down) }}$ & Gage (up) & down & up \\
\hline 10 th & 0 & 0 & 0 & & \\
\hline 8 th & 5.0701 & 5.0700 & 5.0697 & -0.1 & -0.4 \\
\hline 6 th & 10.8746 & 10.875 & 10.8745 & +0.4 & -0.1 \\
\hline 4 th & 16.6595 & 16.6590 & 16.6587 & -0.5 & -0.8 \\
\hline $2 n d$ & 22.4384 & 22.4380 & 22.4382 & -0.4 & +0.2 \\
\hline oth & 31.0338 & 31.0335 & 31.0332 & -0.3 & -0.6 \\
\hline
\end{tabular}

\subsubsection{ACCURACY TO A LIQUID SURFACE AND HYSTERESIS TESTS}

Servo-operated cable gages either reduce or eliminate offset errors that can be introduced into automatic gage measurement by drag in the bearings or nonlinearities in the spring motors. Measuring hysteresis of a gage at closely spaced levels is adequate to characterize the measurement accuracy of a servo gage. However, hysteresis in an automatic gage should be tested over the entire height range of the gage. Some manufacturers use a single liquid level to test automatic gages over the measurement range by coiling and storing the of tape at the float. 0thers use devices for measuring the effect of the spring motor tension over the length of the tape.

The performance of this level gage when measuring a liquid surface was tested in the air shaft facility by placing a vessel of water on each reference surface large enough for the float. This vessel containing the float is shown in figure 7 . The water level was maintained at a fixed height above the reference surface by a $9.5 \mathrm{~mm}$ 0.D. overflow pipe. The pipe passes vertically through the notch in the reference plate with the end open and about $7 \mathrm{~cm}$ above the vesse 7 bottom. The pipe is soldered through a brass block which is clamped to the reference surfaces so the open end of the pipe is always the same distance above the reference surface. A $13 \mathrm{~mm}$ diameter hole up the center of the float permits the float to be placed over this tube. The bolt, nut and locknut used to attach the float to the tape was removed and replaced by an $8 \mathrm{~mm}$ diameter tube to provide a vent so the water height in the hole would be the same as in the rest of the vessel. A spring, washer and split key kept the tube vertical on the float; a second split key attaches it to the link.

The measurement process consisted of attaching the constant level pipe and water vessel to the reference level at which the gage was to be tested and pouring in sufficient water so that when the float was placed in the vessel, water overflowed. The water contained a small amount of detergent to reduce the surface tension. After the water drained down to a low flow rate and the gage reading had stopped changing, the gage was read. Then the float was raised about $1 \mathrm{~cm}$ and allowed 


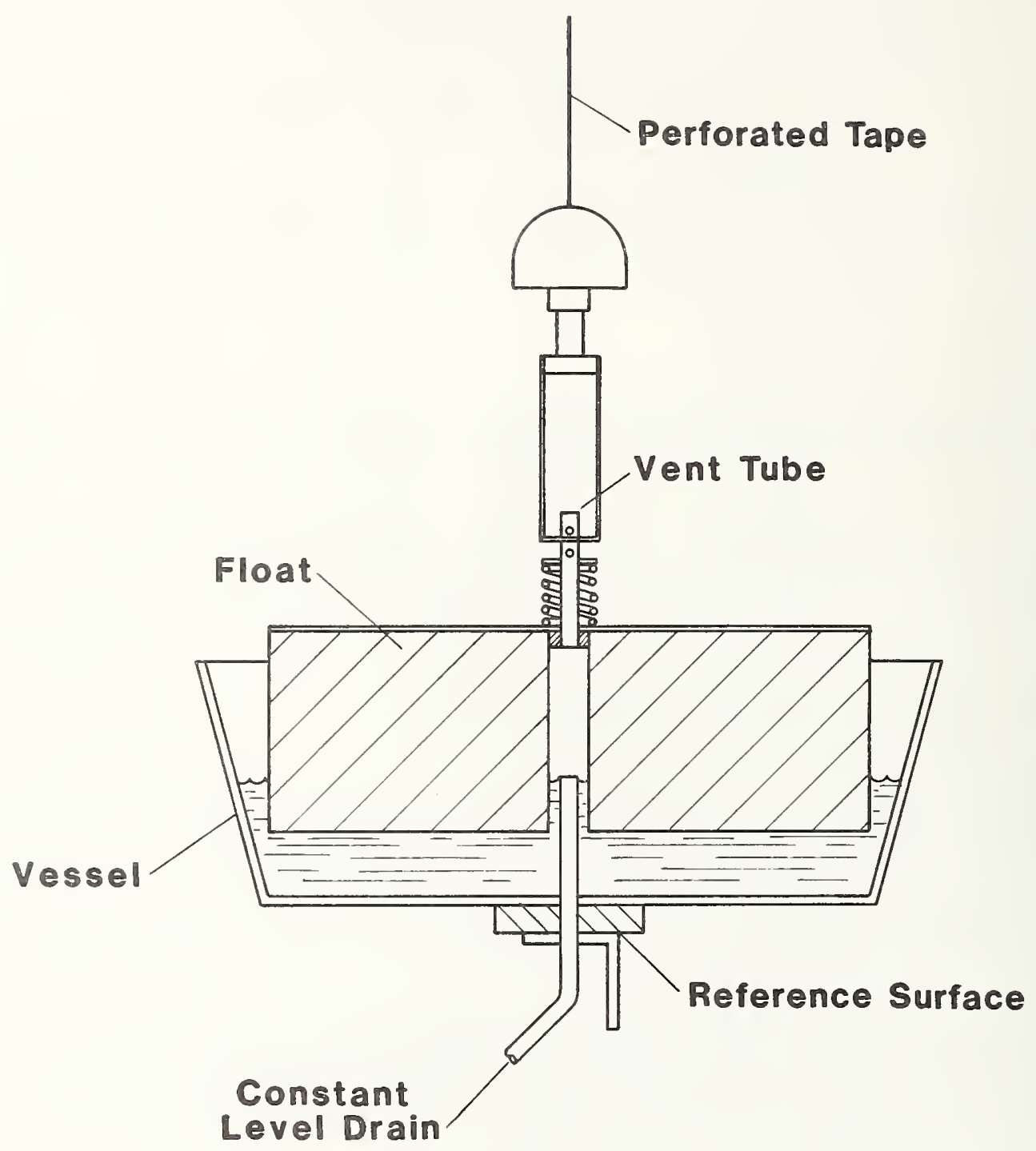

Figure 7. Schematic of the liquid reference surface device. 
to drop. When the gage reading was stable again, the reading was recorded and 50 to 100 cc of water was added to the vessel and allowed to drain away. When the draining had again nearly ceased, the gage reading was recorded. This raise and refill cycle was repeated at least once. After refilling, the gage was read when the flow dropped to the same rate rather than when the flow stopped completely. The gage reading had ceased changing well before a reading was recorded.

The data were recorded at each reference level for four trips, two down and two up the shaft. The differences measured between reference levels are shown in table $6 \mathrm{a}$. Agreement is assumed between the gage and reference at the highest level. The latched position which is used in service as a calibration reference point, is included. The reference surface separations are averaged for the measurements and compared to the tape determined reference level separations in table $6 \mathrm{~b}$ and figure 8 . The bars on each data point in the figure show the full spread of the scatter in the data. The $3.2 \mathrm{~mm}$ bias can be expected to rise to $6.4 \mathrm{~mm}$ for a liquid of $500 \mathrm{~kg} / \mathrm{m}^{3}$ density.

The small scatter of the data relative to the bias suggest that a correction could be applied, therefore a measurement accuracy of $\pm 1 \mathrm{~mm}$ is possible under laboratory conditions, well within the manufacturer's estimated uncertainty of $\pm 1 \mathrm{~cm}$.

The $\pm 0.5 \mathrm{~mm}$ scatter of the data has not been separated into the error due to the water level variation and the error due to the gage. The difference between the average float position when water was added and the position after the float was raised and dropped was usually less than 0.5 $\mathrm{mm}$, and only occasionally slightly over. Some of the scatter could result from variations in the water level, the extent of which could not be easily determined. The hysteresis, then, in this gage is about $0.5 \mathrm{~mm}$ and possibly less.

These measurements suggest that a correction can be applied to the gage for the offset due to the spring motor tension bringing the gage into the same accuracy range as servo gages. However, the accuracy of this gage is probably more sensitive to wear and contamination than servo gages so the accuracy could decrease with time in service.

\section{BUBBLER TYPE LEVEL GAGES}

\subsection{GAGE DESCRIPTION}

Bubbler level gages and differential pressure level gages have been described in the literature by M. P. Wilson, Jr. (13) Since these gages are usually assembled from commerically available components rather than manufactured as a package, no manufacturer's literature was found. The principle of measurement is simple. The hydrostatic head of the liquid at the tank bottom is measured and converted to the liquid height in the tank by dividing by the liquid density. The density must be measured or calculated. The head pressure of a $25 \mathrm{~m}$ depth tank filled with liquid methane at a density of $400 \mathrm{~kg} / \mathrm{m}^{3}$ is:

$$
P=\left(g_{0} \times 1000 \mathrm{~g} / \mathrm{cm}^{2}\right)
$$

If $\mathrm{g}_{0}$, the acceleration of gravity, is in $\mathrm{cm} / \mathrm{sec}^{2}$ then the pressure is in Pascals. If a tank is to be gaged to $1 \mathrm{~mm}$, the pressure gage must resolve pressure to $1 / 25,000$. Accuracies of 1 part in 10,000 of full scale are available with some of the commercially available pressure measuring instruments, however, this is a resolution of only $2.5 \mathrm{~mm}$ in a $25 \mathrm{~m}$ deep tank.

Both bubbler gage methods and static differential pressure measurement methods for LNG service are described by Wilson. The differential pressure method wherein a differential gage is connected across the top and bottom of the tank is commonly used where penetrations into the bottom of the tank are permitted. Since tank penetrations are often not allowed at the bottom of LNG tanks especially ship tanks and pressure gages are operated only with difficulty at low temperature, static differential gages often cannot be used in $L N G$ service. The uncertainties of $\triangle P$ gages should be similar in magnitude to bubbler gages excluding the dynamic pressure drops in the latter. 
Table 6. Fourth cable gage results

Table $6 a^{--}$-Gage readings

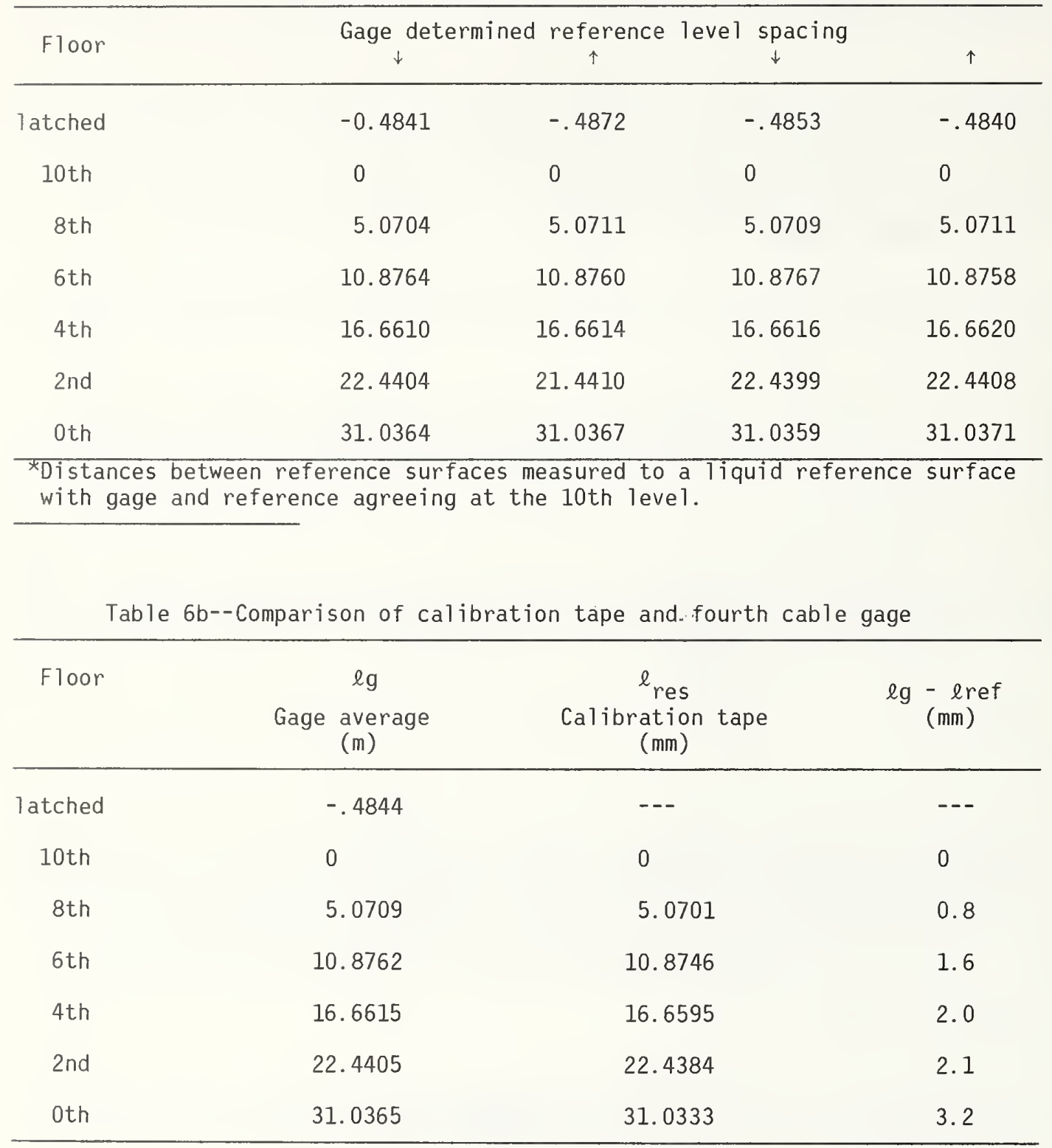




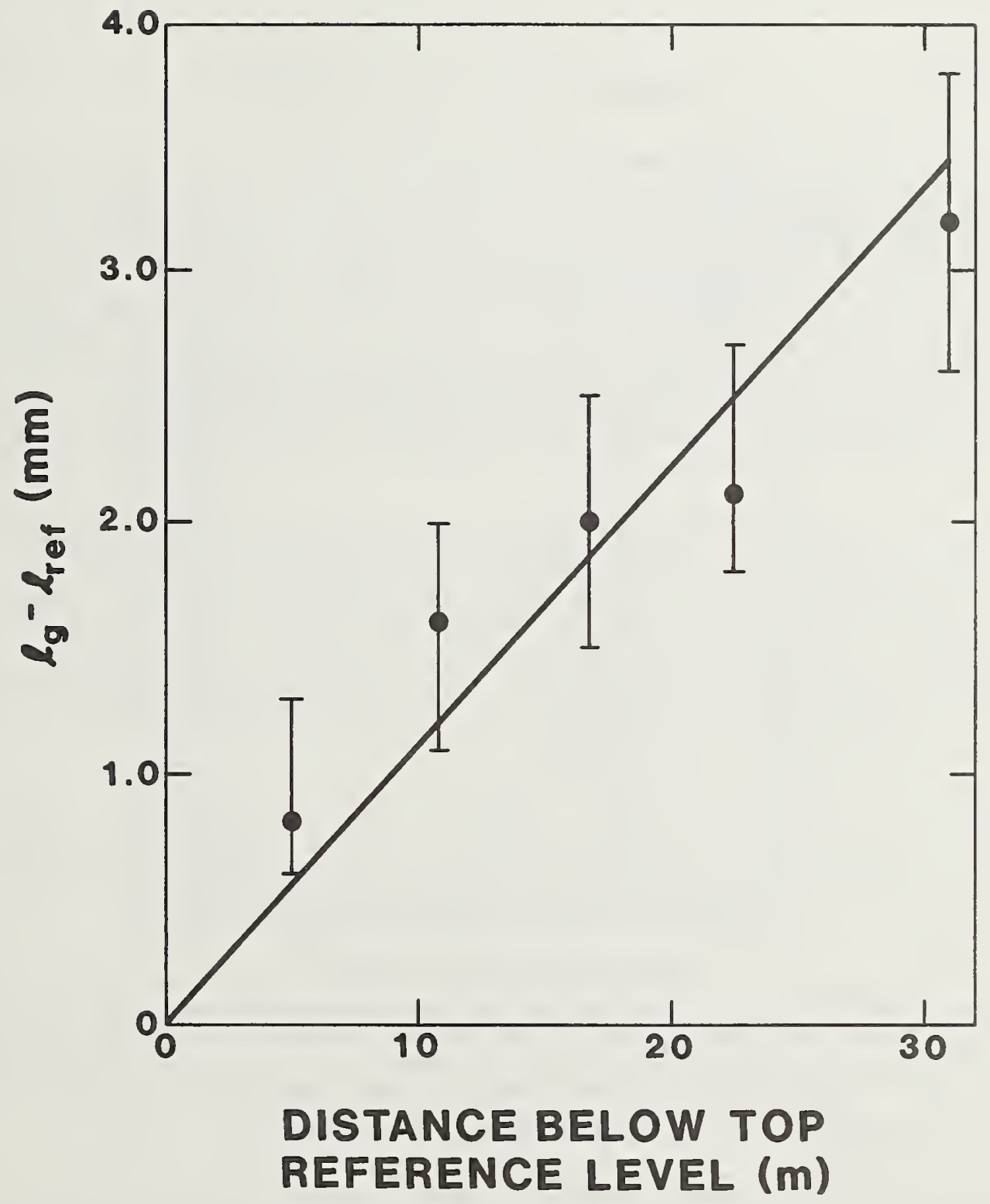

Figure 8 . Results of the accuracy tests of the fourth cable gage. 
Two variations of the bubbler gage from the description by Wilson are shown in figure 9 . The extra tube and $\Delta \mathrm{p}$ gage in the right side of figure 9 provides sufficient information so the 1 iquid density in the region $\mathrm{h}$ can be calculated. The bubbler gage design on the right side illustrates a method of eliminating any pressure drop occurring in the bubbler line. When gas is bubbling through the lines shown in figure 9, the pressure measured by the $\Delta p$ gage is the head pressure of the liquid above the bottom end of the bubbler tube.

An alternative method of measuring the liquid head is illustrated by Wilson but not shown here. Liquid gas interface detectors are located at the bottom of the tube and when this interface is properly centered by adjusting the static pressure in the tube to the tank bottom the pressure is recorded.

\subsection{MEASUREMENT ERROR}

The uncertainties discussed here are for the $25 \mathrm{~m}$ deep tank discussed in section 5.1.

If the gas in the bubbler tubes were weightless, then the $\Delta \mathrm{p}$ observed would be the hydrostatic head. Since the gas has mass, a head pressure also exists for all the gas between the liquid and the gage. The magnitude can be illustrated by the head correction for the bubbler line when the tank is ful1. The absolute pressure is then 2 bar in the bubbler line and the head correction is somewhere between $\left(g_{0} \times 6 \mathrm{~g} / \mathrm{cm}^{2}\right) \mathrm{Pa}$, for the nitrogen gas at ambient temperature and $\left(\mathrm{g}_{0} \times 16^{\frac{1}{2}} \mathrm{~g} / \mathrm{cm}^{2}\right) \mathrm{Pa}$ if the nitrogen gas is at the methane boiling temperature. Furthermore, since methane is a little over half as dense as nitrogen and probably fills the reference side of the $\Delta p$ measurement, an additional correction of about $\left(\mathrm{g} \times 11.7 \mathrm{~g} / \mathrm{cm}^{2}\right)$ Pa for each meter the gage is placed above the tank is required. This decreases as the tank level drops to about $\left(\mathrm{g}_{0} \times 0.5 \mathrm{~g} / \mathrm{cm}^{2}\right) \mathrm{Pa}$ as the tank approaches empty but now, the height from the liquid to the gage is much larger so the total correction required is still 1arge. An uncertainty in the pressure correction of $\left(\mathrm{g} \times 1 \mathrm{~g} / \mathrm{cm}^{2}\right) \mathrm{Pa}$ is a $2.5 \mathrm{~cm}$ error in the liquid level measurement for a liquid with a $400 \mathrm{~kg} / \mathrm{m}^{3}$ density.

The density measurement should be made near the bottom of a tank to provide a density value at low filling levels. If $h$ in figure 9 represents $10 \%$ of the tank height, then the difference of the two gage readings from eq 5.1 wi 11 be $\left(g_{0} \times 100 \mathrm{~g} / \mathrm{cm}^{2}\right) \mathrm{Pa}$ for 1 iquid methane of $400 \mathrm{~kg} / \mathrm{m}^{3}$ density. The pressure gages can introduce a $1 \%$ error in the density measurement if they are $0.1 \%$ gages. Also, the uncertainty in the bubbler line nitrogen gas density contributes to the density uncertainty. The density measurement in a full tank may not represent the density at other levels in the tank especially in a shore storage tank where stratification can take place. The bubbling nitrogen also could alter the local density around the bubblers. A density measurement uncertainty of $1 \%$ does not seem unlikely. An error of $1 \%$ in density introduces an uncertainty of $1 \%$ in the level even before the gas column uncertainties are included.

If the gas is bubbling into the tank, probably the bubbler line contains $N_{2}$ but a pressure drop is present in the line. If the static method shown in figure 9, left side, is used or the interface detector method, the composition of the gas in the lines can be expected to be some mixture of methane and nitrogen. The uncertainty of the gas column density could easily be as large as any pressure drop that might be experienced in a line through which gas is flowing.

Bubbler gages have been relegated to backup use for capacitance gages on ship tanks. Gage accuracy has probably been a factor in this but reliability has been a large consideration too. Very dry clean gas, usually nitrogen gas, must be used or the bubbler nozzles rapidly plug with ice or other solids. Plugging has been a problem. Any leak in the lines from the pressure gage to the tank result in a false level reading and errors introduced by small leaks can easily go undetected.

\subsection{CONCLUSIONS, BUBBLER GAGE}

A bubbler gage can easily be in error by tenths of a meter in a $25 \mathrm{~m}$ tank mainly because of uncertainty in the liquid density measurement and several centimeters additional because of uncertainty in gas head corrections. The poorer accuracy, along with failure due to leaks and plugging, limits the application of these gages to back up use for custody transfer measurement. If the gaging application does not require high accuracy, $\Delta \mathrm{P}$ and bubbler gages have advantages. They are least affected by surface turbulence thus are useful for level monitoring during rapid filling of a tank. 


\section{Bubble Level Gages}

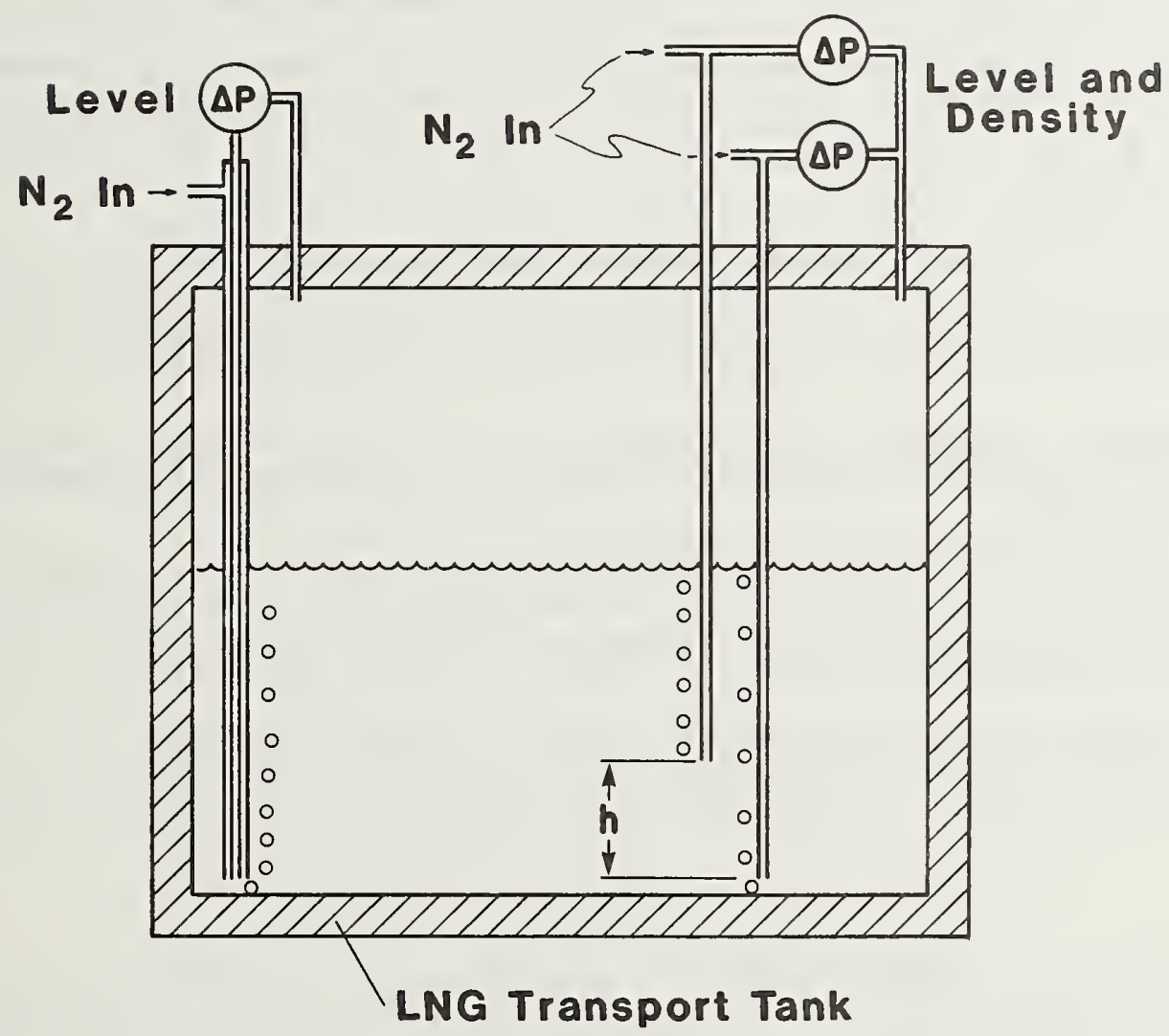

Figure 9. Schematic of some bubbler gages for LNG service. 


\section{CONCLUSIONS}

\subsection{CAPACITANCE GAGES}

Level measurement uncertainty is estimated to be 7.5 and $10 \mathrm{~mm}$ by the manufacturers. Based on tests in freon by one manufacturer, these estimates are conservative since the freon tests showed an uncertainty no larger than $\pm 3 \mathrm{~mm}$. However, a number of uncertainties, whose effect has apparently not been tested directly, arise when the gage is used in LNG. Foaming of the LNG and coating of the tube surface can cause errors if either occurs. Temperature and composition differences of gases and liquids in the active sections introduce errors. Drift of the electronics between the time of calibration and the time of measurement has the potential to cause errors. Laboratory tests in an LNG environment or at least tests in an LNG tank against an accurate standard are needed to obtain better estimates of capacitance gage measurement uncertainty for LNG service.

\subsection{CABLE GAGES}

Tests at ambient conditions in this laboratory of four representative gages of the cable type show that all can measure level in the laboratory to precisions of around $\pm 1 \mathrm{~mm}$ or better. The tests of three of the four instruments showed small systematic errors but those can be removed by calibration. The accuracy of the gages tested should be quite sufficient for most applications as long as the operating temperatures are near ambient and isothermal and the gage head mounting does not change height. The servo gage described in section 4.4 has been designed to eliminate at least partially the temperature and head movement effects.

Appendix A treats the level measurement error due to the tank environment and gives rough estimates of the magnitudes of these errors. They are 10 to 100 times as great as the intrinsic uncertainty of the gage. The errors generated by the environment can be significantly reduced by the use of the compensation methods discussed in Appendix A.

Compensating a cable gage could make it more accurate than a capacitance gage. A compensated gage would cost much less and be more easily removable for repairs. The capacitance gage still has the advantage of no moving parts.

The servo gages are designed with electrical delays in the feed back circuits so that a disturbed 1 iquid surface does not cause the gage to hunt. The servo gages do not move until the average level over time, changes. Wear is subsequently less and because of the feedback, wear should not have a large effect on the accuracy.

The automatic gage tested is completely mechanical and has no damping system. It is a marine version of the commonly used float gage. The automatic gage tested showed a laboratory accuracy if calibrated of better than $\pm 1 \mathrm{~mm}$. How well this level of accuracy would hold as the gage wears is not known.

\subsection{BUBBLER GAGES}

Commercially available pressure gages can probably measure pressures accurately to an equivalent to about $2 \mathrm{~mm}$ of liquid height. Gage temperature and composition uncertainties in the pressure measuring 1 ines will degrade the accuracy of the height measurement. The dominant uncertainty in the level measurement, however, is the determination of the density of the liquid which is necessary to change pressure to a height. A $1 \%$ error in the density determination introduces a $1 \%$ error in the gaging of a tank. Leaks can cause erroneous pressure readings and impurities in the bubbling gas can plug the lines. The limitations on bubbler gage accuracy for custody transfer measurement cannot be easily eliminated.

\section{ACKNOWLEDGMENTS}

The author wishes to thank the manufacturers and users of gages who provided information for this report and the gage manufacturers who provided the cable gages tested. The author also wishes to thank the Physics Department of the University of Colorado, and especially John C. Groft and Professor Albert Bartlett of that department, for making the airshaft in Gamow Tower available for the cable gage tests. 


\section{REFERENCES}

[1] Armstrong, G. T., Hydrocarbons for Fuel -- 75 Years of Materials Research at NBS, Nat. Bur. Stand. (U.S.) Spec. Publ. 434 (May 1976).

[2] Haynes, W. M. , Hiza, M. J. and McCarty, R. D., Densities of LNG for custody transfer, LNG 5 , International Conf. on Liquefied Natural Gas, Proc. 5th (Dusseldorf, Germany, Aug 29-Sep $\overline{1}$, 1977), Vol 2, Session III, Paper 11 (Institute of Gas Technology, Chicago, I11., 1977).

[3] McCarty, R. D., Four Mathematical Models for the Prediction of LNG Densities, Nat. Bur. Stand. (U.S.) Tech. Note 1030 (Dec 1980).

[4] Brennan, J. A., Better LNG flow measurement sought, 0 il Gas J. 76(5), 168+173-4+177 (Jan 1978).

[5] Parrish, W. R., Arvidson, J. M. and LaBrecque, J. F., Development and Evaluation of an LNG Sampling System, Nat. Bur. Stand. (U.S.) NBSIR 78-887 (JuT 1978).

[6] Jackson, R. H. F., Collier, R. S., Haber, S. and Tryon, P. V., Custody Transfer Systems for LNG Ships: Tank Survey Techniques and Sounding Tables, Nat. Bur. Stand. (U.S.) NBSIR $7 \overline{9-}$ 1751 (1979).

[7] Haight, R. J., Hocken, R. J., Borchardt, B. R., Carro11, C. L., Hartsock, R. G., Reeve, C.P., Scire, F. E. and Veale, R. C., Estimated Accuracy of Calibration of Some Membrane-Type LNG Transport Tanks, Nat. Bur. Stand. (U.S.) NBSIR 80- $\overline{21} 4 \overline{1}$ (1981).

[8] Hocken, R. J. and Haight, W. C., Multiple redundancy in the measurement of large structures, CIRP Ann. 27, 357-60 (1978).

[9] Siegwarth, J. D., Younglove, B. A. and LaBrecque, J. F., An Evaluation of Commercial Densimeters for Use in LNG, Nat. Bur. Stand. (U.S.) Tech. Note 697 (0ct 1977).

[10] Siegwarth, J. D. and LaBrecque, J. F., A Portable Calibration Densimeter for Use in Cryogenic Liquids, Nat. Bur. Stand. (U.S.) Tech. Note 1035 (Mar 1981).

[11] Siegwarth, J. D. and Labrecque, J. F., Cryogenic Fluid Density Reference System: Provisional Accuracy Statement (1980), Nat. Bur. Stand. (U.S.) Tech. Note 1041 (Jun 1981).

[12] Roder, H. M., ASRDI 0xygen Technology Survey Volume V: Density and Liquid Level Measurement Instrumentation for Cryogenic Fluids 0xygen, Hydrogen, and Nitrogen, NASA SP-3083 (1974).

[13] Wilson, Jr., M. P., "LNG Tank Level Measurement," AGA Operating Section Proceedings, Proceedings of the Transmission Conference, Las Vegas, Nevada, T-223 (1976).

[14] Jelffs, P. A. M., "Calibration of Containers and Gauges," Journal of the Institute of Petroleum, $\underline{58}, 118$ (1972).

[15] Paterson, I.W.F., "Standardization for Installation of Automatic Gages," Journal of the Institute of Petroluem, 58, 209, (1972).

[16] Watson, P. B., Journal of the Institute of Petroleum 58, 126 (1972).

[17] Halverson, G., "Automatic Continuous LNG Level-Gauging and Temperature Measuring Systems," Instrumentation in Cryogenic Industry, 1, paper 602 Houston, Texas, (1976).

[18] Williams, R. A., "High Accuracy Level Gaging," Proceedings 55th International School of Hydrocarbon Measurement, Norman, Oklahoma (1980) pg 332. Similar papers appear in 1977 to 1982 schools. Also, see Moore, C. F. and Blanchard, R. L., "Custody Transfer Instrumentation Systems for LNG Marine Transport Projects", Fourth International kConference on Liquified Natural Gas, Algiers, Algeria (1974). 
[19] Eilers, C., "Modern Automatic Tankgauging Systems," Proceedings 55th International School of Hydrocarbon Measurement, Norman, 0klahoma (1980) pg 345.

[20] Unpublished report of gage tests in a freon by manufacturer.

[21] LNG Materials and Fluids - A User's Manual of Property Data in Data in Graphic Format, by D. B. Mann, Editor. Manual sponsored by American Gas Association, Maritime Administration, Office of Standard Reference Data and American Bureau of Shipping. Published by National Bureau of Standards, Thermophysical Properties Division 773, Boulder, Colo., 325 pages (1977).

[22] Siegwarth, J. D. and LaBrecque, J. F., "Estimated Uncertainty of Calibrations of Free Standing Prismatic Liquefied Natural Gas Cargo Tanks." NBSIR to be published. 
APPENDIX A

Level Measurement Errors

Caused by LNG Tank

Environments 


\section{LEVEL-MEASUREMENT ERRORS CAUSED \\ BY LNG-TANK ENVIRONMENTS}

\section{J. D. Siegwarth}

\section{Introduction}

Custody transfer of liquefied natural gas (LNG) is currently accomplished by static measurements of volume. The liquid levels in calibrated tanks, usually transport tanks, are measured before and after the custody transfer operation to determine the volume of LNG changing ownership. When a level measurement is made in an iso-thermal and geometrically unchanging tank, the total error of the measurement is the combined systematic and random error of the level gage. Most tanks and especially LNG tanks are neither isothermal nor geometrically unchanging. Thus, the tanks introduce additional systematic errors into the level measurement. The size of these additional systematic errors, which will be called tank systematic errors henceforth, depend on the type of level gage, the method of installation and the variation with time of various tank parameters such as temperature and internal pressure. The systematic and random error of some types of gages can be determined in the laboratory. The tank systematic error, which in many cases dominates the measurement error, does not lend itself readily to laboratory examination.

Though a number of different physical principles have been incorporated into cryogenic level measuring devices [1,2], only two general types are now commonly installed for accurate LNG leve] measurement. Systematic errors for one of these types called here the cable type $[3,4]$ are discussed here.

A cable gage consists of a surface sensing unit such as a float suspended on a cable, tape or wire. A control unit consisting of some sort of mechanical device or servo mechanism maintains the sensor at the liquid surface and measures the length of tape, cable, or wire wound or unwound from a storage drum when the liquid surface is raised or lowered. This control unit is usually mounted externally on the top or near the base of the tank. The level may be displayed on a mechanical or electronic counter at the control unit or electrically at a remote site. This type of gage, which will for brevity be called a cable gage in the remainder of this paper, can be adapted to measure level of most liquids.

The second type, the capacitance level gage [5] consists of a coaxial cylindrical capacitor with a length equal to the tank height, mounted so the axis is perpendicular to the liquid surface. because the liquid has a higher dielectric constant than the gas, the capacitance is proportional to the height of the liquid between the coaxial tubes. This type of gage is suitable mainly for cryogenic service since the electrical conductance of the liquid must be small and the capacitor plates cannot become permanently coated with the liquid. Systematic errors associated with this type wi11 not be discussed here.

Though the following discussion is applied to LNG tank gaging, the analysis of the cable gages applies equally well to gaging any other liquid. Other authors have briefly discussed tank systematic errors associated with some of the level gages $[3,6,7]$.

\section{Errors Associated With Some Typical Cable Gage Installations}

\section{Tank-Top Mounting}

Figure 1 illustrates a common method of installing a level gage on a typical LNG tank. The gage head (1) may be mounted anywhere from the center to the edge of the outer tank roof. The liquid surface sensor (2) may or may not be located in a stilling well (3) and is suspended by the cable (4). The design is a typical large above-ground LNG storage tank design consisting of a cold inner tank with liquid-tight sides and bottom (5) and a gas-tight outer container (6) at ambient 


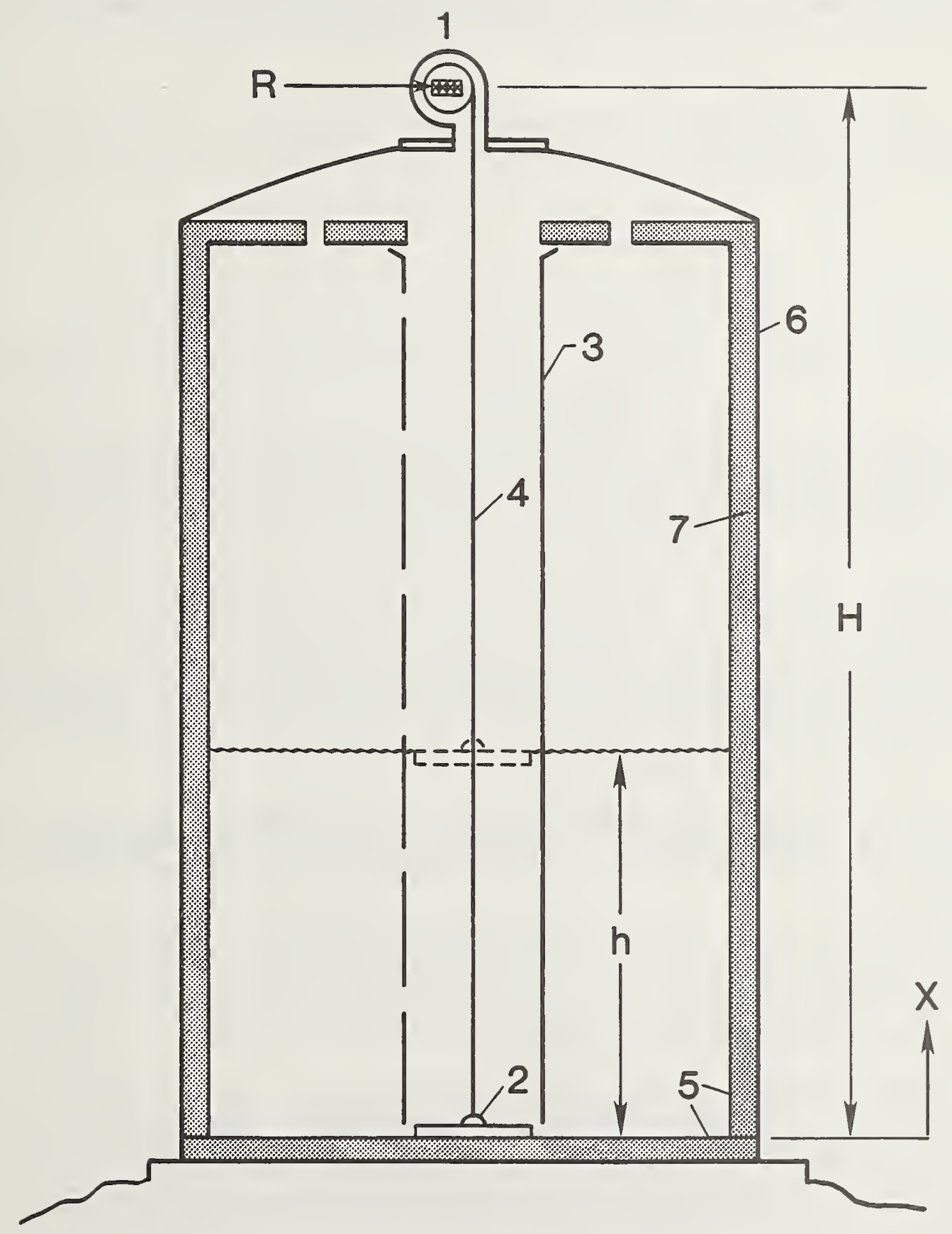

Figure 1. Schematic of an LNG tank and a roof-mounted level gage. 
temperature. The space between the walls and the floors of the two tanks contains insulation (7). The ceiling of the inner tank is suspended from the domed roof of the outer tank and serves mainly to support insulation.

Assume, as starting conditions for the analysis of the tank systematic gaging errors, that the tank is empty, isothermal at ambient temperature, and at atmospheric pressure. The sensor rests on the tank bottom. Under these conditions, the gage reading is $R$ which could be, but is not necessar$i l y$, zero. As the inner tank is cooled, the cable shrinks and the reading $R$ is now

$$
R=R_{a}+1_{c}
$$

where 1 is the thermal change of the cable length. The cable shortens so more cable unwinds to reach the bottom of the tank hence $R$ is less than $R_{a}$. The length change of the cable is given by

$$
1_{c}=\int_{0}^{H_{B}} \beta_{c}(T) d x
$$

where $H$ is the height of the tank and the thermal expansion $\beta_{c}(T)$ is defined here as:

$$
\beta_{C}(T)=\frac{L_{C}(T)-L_{C} \text { (ambient) }}{L_{C}(\text { ambient })}
$$

Here, $L_{c}$ is a length of cable and $T$ is the temperature which is a function of both the elevation $x$ and the ${ }^{c}$ time $t$. That is,

$$
T=f_{c}(x, t)
$$

and $\beta$ at time $t$ is a function of $x$. The correction 1 in eq (2) can then be calculated provided $f_{c}(x)$, the temperature distribution in the ullage space has been measured.

If the gage mounting point or support moves up by either thermal expansion of the tank shell or increasing pressure difference between the inside and outside roof surfaces, the gage reading decreases. Including the roof movement in eq (1),

$$
R=R_{a}+1_{c}-1_{s}-1_{p}
$$

where 1 is the thermally generated change of height of the tank outer shell, defined by equations identical to (2), (3), and (4) except the subscript $c$ is replaced by $s$ to designate the she11, and 1 is the change of roof elevation resulting from the pressure change. The pressure, hence $1_{p}$, is

If the tank is cooled and filled with LNG to the height $h$ while holding the sensor fixed to the tank bottom, $R$ is given by eq $(5)$, but the ${ }^{1}$ term can be split into the portion below the LNG
surface and that above:

$$
\left.\left.R=R_{a}+1_{c}\right]_{h}^{H}+h \beta_{c}\left(T_{1}\right)-1_{s}\right]_{0}^{H}-1_{p}
$$

where $]^{\mathrm{H}}$, for example, shows the limits of the integral defining 1 , (eq 2). Since the LNG is at its boiling point, the liquid temperature gradient is assumed smal $\}^{\prime}$. Thus in the liquid $\beta(T(x))$ is constant. Then $l_{c}$ in this region integrates to the product of $h$ and $\beta_{c}$ ( $T_{1}$ ) as shown in eq (6) where $T_{\text {f }}$ is the liquid boiling temperature. The surface sensor is now refeased and allowed to seek the surface. After the temperature distribution of the cable from $h$ to $H$ again assumes the gas temperature along its length, a length of cable $h\left(1-\beta_{c}\left(T_{1}\right)\right)$ has passed into the gage head. This adds to the left side of eq (6) to give R. Since $\beta_{\text {i }}$ i negative (see eq 3 ), a length of cable longer than $h$ has been wound. The gage reading is now,

$$
\left.\left.R=R_{a}+1_{c}\right]_{h}^{H}-1_{s}\right]_{0}^{H}-1_{p}+h
$$

because the $\beta_{c}$ terms cancel. 
Equation (7) is a general expression that can be applied to any gage installation by introducing the $\beta$ and $\beta$ for the materials of the gage cable and support structure respectively and integrat-

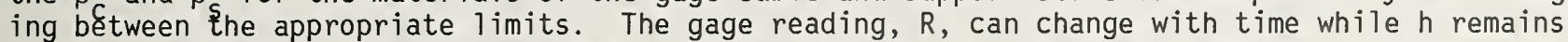
constant because the time dependence in $T$ and $P$ introduces a time dependence in the three 1 terms.

Usually the difference between two levels $h_{2}-h_{1}$ is the quantity desired rather than an absolute value for $h$. Thus, subtracting eq (7) for $h_{1}$ from the same equation for $h_{2}$ and solving for $h_{2}-h_{1}$ gives

$$
\begin{aligned}
h_{2}-h_{1}= & \left.\left.R_{2}-R_{1}-\left(1_{c 2}\right]_{h_{2}}^{H}-{ }_{c 1}\right]_{h_{1}}^{H}\right) \\
& \left.+\left(1_{s 2}-1_{s 1}\right)\right]_{0}^{H}+1_{p 2}-1_{p 1}
\end{aligned}
$$

When the level changes the 1 term difference will not be zero nor will the 1 term difference be zero because the tank pressure can be expected to change when the level changes. The $1_{5}$ term difference is non zero if the external temperature is changing.

The 1 and 1 corrections can in principle be calculated if the temperature distributions as a function of height of both the gas space and the shell of the tank are known. The former may be measured since the temperature profiles of the contents are usually measured but the outer shell temperature distribution is probably not measured. In both cases corrections, if made, are likely to be based on estimates rather than temperature measurements.

Gage Head Mounted at Ground Level

Gage I diagrammed in the tank in figure 2 is a gage installation similar to that recommended in British Standard $3792 / 1964$. The tank is of the same design as that in figure 1 . This installation method is independent of the tank roof if the flex section (3) has sufficient flexibility to eliminate any thrust on the gage guide arm (1). However, the arm end (1) does move up and down with temperature because of thermal expansion of the tape guide which is anchored at the bottom of the shell while the remainder is allowed to slide in the mounting brackets.

In the expression for the gage reading as a function of height, eq (7), both 1 and 1 are now calculated by integrating along the path of the cable, that is, from 0 to $2.1 H^{5}$ for the installation diagrammed in figure 2 gage $I$. The expression for $R$ is,

$$
\left.\left.R=R_{a}+1_{c}\right]_{h}^{2.1 H}-1_{s}\right]_{0}^{2.1 H}-1_{p}+h \text {. }
$$

The integrals from 0 to $H$ are essentially the same as for the gage installation shown in figure 1 except now the expansion of the guide tube rather than the tank enters the expression for 1 . The portion of the integral determining 1 and 1 between $H$ and 2 . $1 \mathrm{H}$ is just the difference between the length of the guide and the cable. The 0.1 h in the guide length allows for the horizontal guide section at the tank top.

The temperature distribution in the guide and enclosed cable can be assumed the same. Thus only differences of $\beta_{c}$ and $\beta_{s}$ give a non zero value to the difference of $l_{c}$ and $1_{s}$ between $H$ and 2.1H.

Any motions in the vertical direction of the end of the arm, (1) due to wind or differential expansion between the guide and brace (3) will be included in the $1_{p}$ term.

The relationship between true level change $h_{2}-h_{1}$, and gage reading $R_{2}-R_{1}$ for this gage installation is obtained by subtracting eq (9) for $R_{2}$ from eq (9) for $R_{1}$. Solving this difference for $h_{2}-h_{1}$ gives 


$$
\left.\left.\left.h_{2}-h_{1}=R_{2}-R_{1}-\left(1_{c 2}\right]_{h_{2}}^{2.1 H}-1_{c 1}\right]_{h_{1}}^{2.1}\right)+\left(1_{s 2}-1_{s 1}\right)\right]_{0}^{2.1 H}+1_{p 2}-1_{p 1} .
$$

Variations of this mounting exclude the flexible section (3) figure 2 gage I at the tank top. The roof-movement error again fully enters measurement as when the gage is roof mounted.

\section{Bottom-Referencing Level Gage}

This type of cable gage drives down, senses the tank bottom for a reference point, then measures the surface. This cycle can take an hour to complete for a full tank. The suspending cable is hollow with electrical leads inside.

The gage reading with the sensor at the bottom, $R_{b}$, is the same as eq (6):

$$
\left.\left.\mathrm{R}_{\mathrm{b}}=\mathrm{R}_{\mathrm{a}}+\mathrm{1}_{\mathrm{cb}}\right]_{\mathrm{h}}^{\mathrm{H}}+\mathrm{h} \beta_{\mathrm{c}}\left(\mathrm{T}_{1}\right)-1_{\mathrm{sb}}\right]_{0}^{\mathrm{H}}-1_{\mathrm{pb}}
$$

where the $b$ subscripts indicate the value with the surface sensor resting on the tank bottom. The gage reading with the sensor at the liquid level is given by eq (7). Combining eqs (11) and (7) and solving for the level $\mathrm{h}$ gives

$$
\left.h=\left\{\left(R-R_{b}-\left(1_{c}-1_{c b}\right)\right]_{h}^{H}+\left(1_{s}-1_{s b}\right)\right]_{0}^{H}+1_{p}-1_{p b}\right\} /\left(1-\beta_{c}\left(T_{1}\right) .\right.
$$

The $1_{p}, 1_{c}$ and 1 terms would cancel if there were no change in the pressure in the tank, the temperature distribution in the ullage of tank or temperature change of the ambient she 11 in the time lapse between sensing the bottom then the liquid level. The contribution of the 1 terms are probably small but not zero. Thus, when the difference of two levels is measured, the bottom must be sensed at each level and the level must be static through the time between the bottom and surface measurements for best accuracy.

\section{Gage Installation Methods Providing Compensation}

Level gages can be installed by two methods that eliminate most of the sources of errors discussed in the previous section. The first method, the stilling well method, is based on the fact that eq ( 7 ) contains the difference between the 1 and 1 terms. Thus, if the temperature distributions are the same and $\beta_{c}(x)=\beta_{s}(x)$ the terms Ean cancel.

The second method, the cable-compensation method is merely a means of measuring the magnitude of the gage-support motion that also includes a measurement of-cable length change.

\section{Stilling-We 11 Method}

The stilling-we11 method is shown by gage II diagrammed in figure 2. The level gage is mounted on the top of the stilling well (5). The stilling well is supported by the floor and passes through a flexible seal (6) in the tank roof. The gage reading for this installation is, from eq (7),

$$
\left.\left.\mathrm{R}=\mathrm{R}_{\mathrm{a}}+\mathrm{1}_{\mathrm{c}}\right]_{\mathrm{h}}^{\mathrm{H}}-\mathrm{1}_{\mathrm{s}}\right]_{\mathrm{h}}^{\mathrm{H}}-\mathrm{h} \beta_{\mathrm{s}}\left(\mathrm{T}_{1}\right)+\mathrm{h} \text {. }
$$

The 1 term, where $1_{s}$ is now the expansion of the stilling well rather than the tank shel1, has been split into a term for the liquid region and a term for the gas region. No pressure term appears because a suitable flexible seal (6) eliminates any pressure effect on the gage support. If the floor settles slightly with filling the gage reference follows it and compensates for the settling provided the mounting point movement reflects the average tank-bottom settling.

If the coefficient of expansion of the cable and pipe are the same and $T_{f}(x, t)$ is the same as $T_{S}(x, t)$ as it almost certainly is since the cable sees only the stilling ${ }^{c}$ well temperature, the term $\left.\left({ }^{-} l_{\S}\right)\right]_{h}$ is zero in eq (13). The actual level difference, $h_{2}-h_{1}$, when the level changes from $h_{1}{ }^{C}$ to $h_{2}$, can be determined by taking the difference between eq (13) expressed for $R_{2}$ and $R_{1}$ and solving for $h_{2}-h_{1}$ 


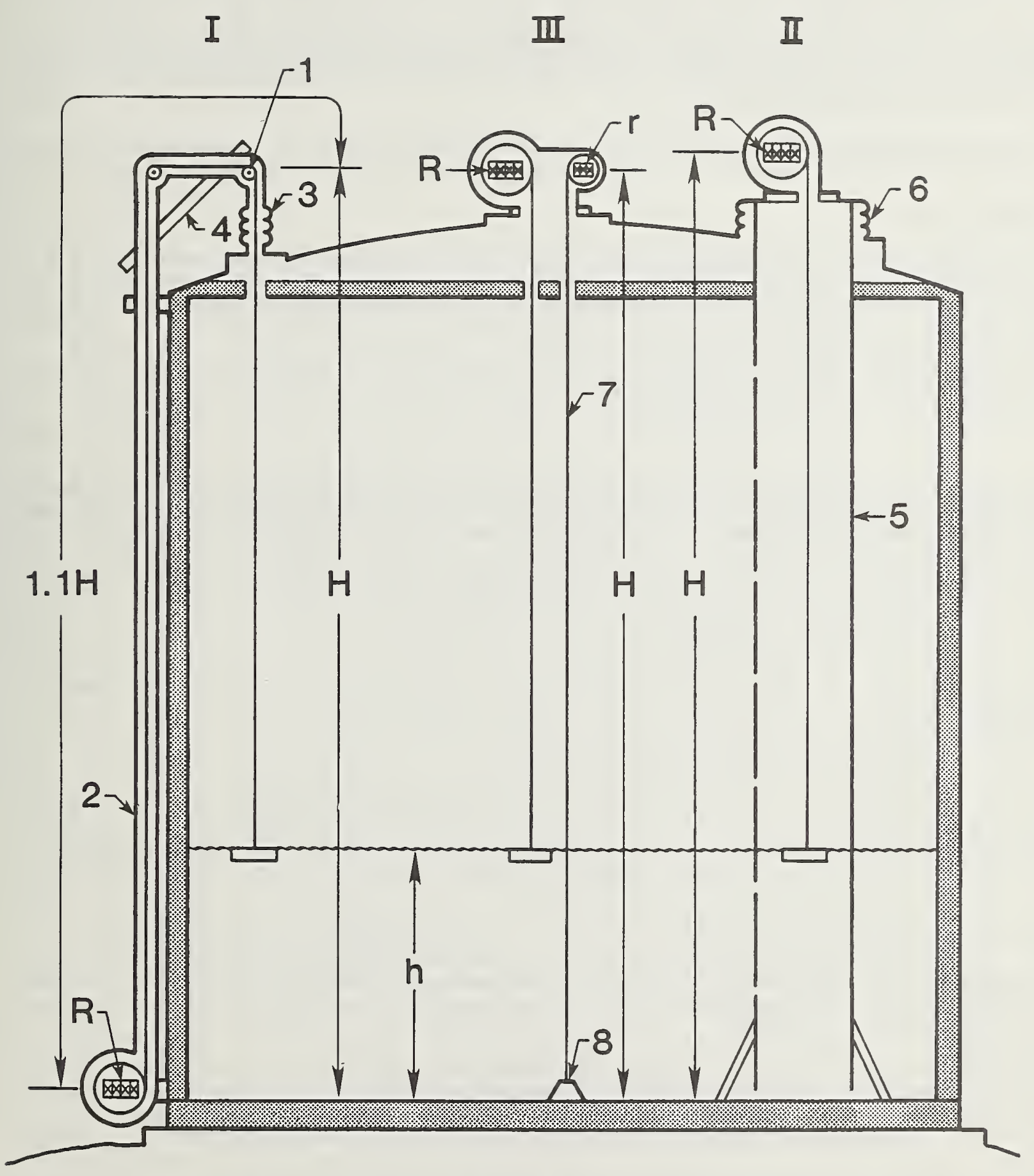

Figure 2. Schematic of a LNG tank showing different leve1-gage installations. I is a ground-level reading gage, II is a stilling-well compensated gage, and III is a cable-compensated gage. Complete descriptions are contained in the text. 


$$
h_{2}-h_{1}=\left(R_{2}-R_{1}\right) /\left(1-\beta_{S}\left(T_{1}\right)\right) \text {. }
$$

The thermal expansion $\beta_{s}\left(T_{l}\right)$ is known for most materials and can be assumed approximately constant because $T_{1}$ changes litt ${ }_{\text {e }}$ with height.

Though this method of installation permits high accuracy, a stainless-steel tube and a tape or wire is probably the only combination practical to use as an expansion-matched cable and support. The expansion of a cable rather than a tape or wire, probably will not match the expansion of the tube even though made of the same material [3].

A stainless-steel stilling well would not only be expensive installed at the time the tank is built but also difficult, if not impossible, to retrofit in an already constructed storage tank.

\section{Cable-Compensated Method}

The second method for a compensating gage installation that can achieve the same accuracy while permitting a wider choice of cable material is gage III illustrated in figure 2. A second or reference cable (7) of the same material as the gage cable is attached to the bottom, preferably by the weight (8). This reference cable could be a guide cable for the level sensor. This cable is attached to another level-readout mechanism which could be another gage head or a more simple device contained within the level-gage head to record small motions. The reference cable reading $r$ is given by a relation identical to eq (6):

$$
\left.\left.r=r_{a}+1_{c}\right]_{h}^{H}+h \beta_{c}\left(T_{1}\right)-1_{s}\right]_{0}^{H}-1_{p}
$$

where again $r$ is the reading with the whole tank at ambient conditions and could be set to zero. This second lêvel indicator records the changes of the reference cable length relative to the gage mounting. These changes are probably no more than $\pm 20 \mathrm{~cm}$ in a $40 \mathrm{~m}$ high tank.

Since this reference cable is chosen to match the coefficient of the gage cable, eq (15) subtracted from eq (7), the expression for the reading of a roof mounted gage, gives

$$
R-r=R_{a}-r_{a}-h \beta_{c}\left(T_{7}\right)+h
$$

The height difference between two levels $h_{2}$ and $h_{1}$ derived from eq (16) is related to the gage and reference readings by:

$$
h_{2}-h_{1}=\left[R_{2}-R_{1}-\left(r_{2}-r_{1}\right)\right] /\left(1-\beta_{c}\left(T_{1}\right)\right) \text {. }
$$

The quantity $r_{2}-r_{1}$ was provided mechanically for a stilling-well mounting when the stilling-well and cable have matched thermal coefficents. This reference cable method permits $r_{2}-r_{1}$ to be read separately and subtracted or subtracted within the readout logic. Cable compensation should be cheaper to install than the stilling-well compensation and can easily be retrofitted to existing tanks.

The reference cable method can be used for correction of the level gage using the bottom as a reference. The stilling-well method would not serve since the hollow cable does not have the same thermal expansion as the bulk material [3]. This compensating method could be used also when the gage head is mounted at grade level provided that the same wire or tape extends all the way from the level sensor to the control unit.

A reference cable can correct any of the gage installations described here for the errors introduced by thermal and mounting effects. If the bottom of the tank settles uniformly relative to the outer shell as the tank fills, the reference cable corrects for this just as does the stilling we11. The errors remaining are primarily the uncertainties in thermal-expansion data and the gage accuracy. 


\section{Qualitative Error Estimate for a Typical LNG Storage Tank}

Maximum values for the various tank systematic gaging errors for a tank $40 \mathrm{~m}$ high by $60 \mathrm{~m}$ diameter are estimated here for the gage installations discussed above. The error estimates are based on the assumption that the gage readings are taken to be the true levels. Some corrections, like the ullage temperature effect on the level have been discussed by other authors and some corrections may be made to level measurements at some installations. Corrections are generally not made for ambient temperature variation of the gage support height or pressure-caused variations of that height.

For the error estimates here, the average temperature of the $u 17$ age is assumed to be $-100^{\circ} \mathrm{C}$. In an actual tank, this temperature is not constant and the temperature distribution varies with time and the filling or emptying of the tank.

The tank outer-shell temperature can vary considerably since the tank contents provide no thermal inertia to the shell as the contents do for single wall tanks containing ambient temperature liquids. The temperature of the shell is estimated to vary over the range of $60^{\circ} \mathrm{C}$ from a hot sunny day to a cold night. The absorption and emissivity of the tank influence this range as well as the weather.

No measured value was found in the literature for the magnitude of the roof movement in the vertical direction due to the pressure of the contents. Estimates range from one to several centimeters [3]. The magnitude of the roof movement depends on the structural design and the magnitude of the internal pressure and the range permitted.

The maximum values for the estimated errors presented in Table 1 are based on the assumption that the tank goes from filled to empty while at the same time, factors introducing the tank systematic errors change from one extreme to the other. The different errors are added to give the total errors discussed below. These total errors are for purposes of comparing the various installation methods and do not apply to any specific installations.

The first line in Table I gives an estimate of the tank introduced systematic errors of a conventional tank top installation. The maximum possible error for a steel tank and stainless steel tape or wire is about $11 \mathrm{~cm}$. A cable could give a larger maximum value [3].

The estimated errors when the gate head is mounted at ground are given in the second line of Table I. A larger number of parts permits a wider variety of materials. The level systematic error varies from slightly smaller to larger than the $4 \mathrm{~cm}$ estimated for a roof mount, line 1 . The use of invar in the ullage reduces the error there but increases the error resulting from expansion differences between the guidetube and cable wire or tape.

The total tank systematic error introduced by the tank structure to the bottom sensing gage line 3 , Table I, is difficult to estimate. Referencing the bottom removes all the error due to tank parameter change if the parameters do not change between sensing the surface and sensing the bottom. In actual cases some change can occur and then the cycle time of the gage is important. A few centimeters total error seems possible.

Estimated errors for stilling-well compensation is given on line 4, Table $I$. The assumption that $T(x)$ of the wire cable or tape and stilling well are equal is reasonable but the assumption that $\beta_{c}(x)$ and $\beta_{s}(x)$ are the same is more dubious, especially for a cable [3]. The manufacture of a tube differs enough from that of tape or wire that making them of the same material might not assure equal expansivity. Thus a total tank introduced systematic error of a stilling well compensating installation could be 2 or $3 \mathrm{~cm}$. A careful choice of materials could reduce the systematic error estimate to a low enough value that gage errors could then dominate.

The error estimate for the cable compensated level gage is given in line 5 of Table 1 . This tank systematic error is estimated to be the smallest because invar can be used for the gage and reference cables thereby reducing the $\beta\left(T_{1}\right)$ contribution to its smallest value. This type of compensation offers the highest flexibility since even a cable, rather than just a wire and tape can be compensated and any material can be used. Two cables, wires, or tapes can more easily be tested in 
Table 1. Maximum estimated errors introduced into level measurement if $\left(R_{2}-R_{1}\right)$ is assumed to be the level change for a 40 meter depth LNG tank with carbon steel outer shel1. NA means "not applicable".

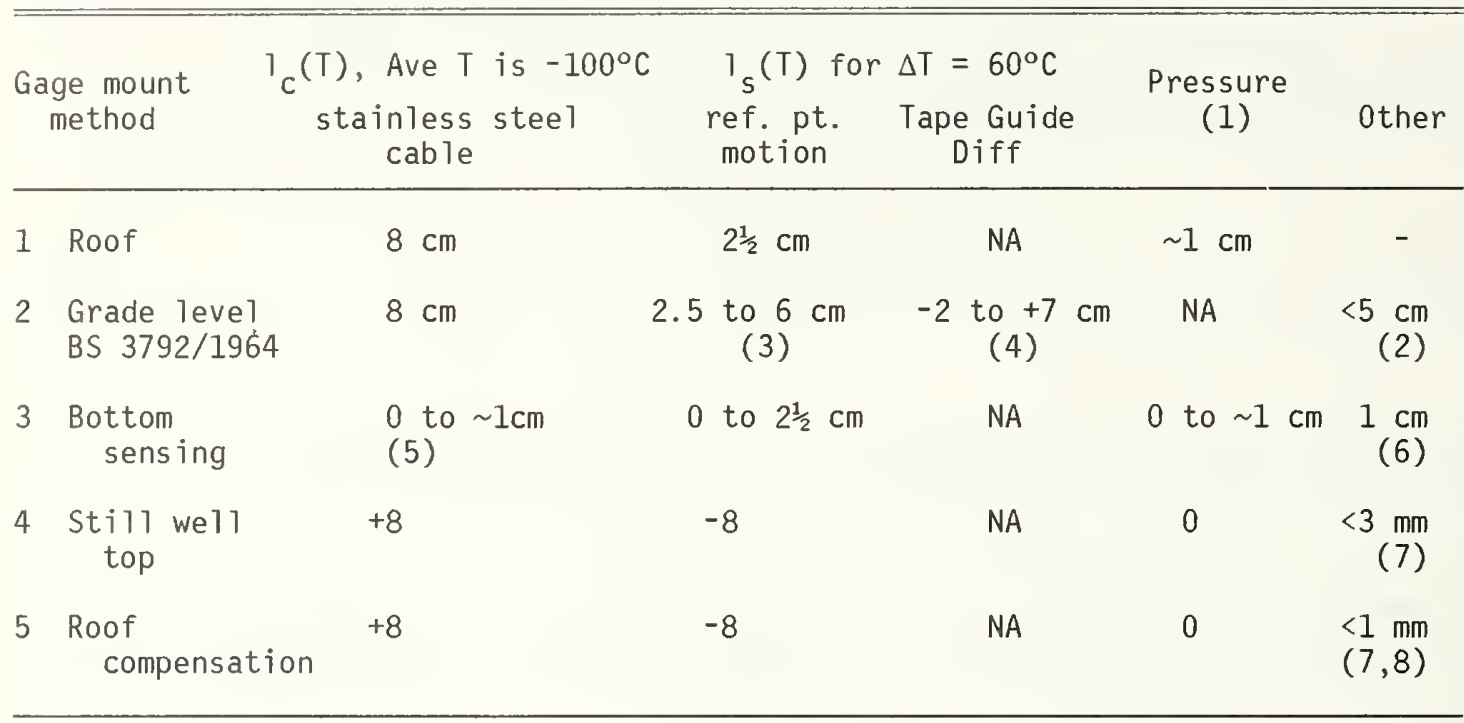

(1) Magnitude depends on flex of roof and whether the gage is near the edge.

(2) Vertical motion of arm end from bending effects of temperature and wind.

(3) $2.5 \mathrm{~cm}$ for steel to $6 \mathrm{~cm}$ for aluminum.

(4) $-2 \mathrm{~cm}$ for carbon steel guide tube and SS cable. $7 \mathrm{~cm}$ for invar cable and aluminum guide tube. Sign gives correction relative to (3).

(5) This estimate is reasonable only if the bottom is referenced before and after a level change.

(6) $\beta_{s}\left(T_{1}\right)$ estimated larger since cable may vary in expansivity.

(7) Uncertainty in $\beta_{5}\left(T_{1}\right)$ of $3 \%$.

(8) Uncertainty in $\beta_{S}^{S}\left(T_{1}\right)$ estimated for invar cable.

*An invar cable can reduce this error to about $1 \mathrm{~cm}$ for the gages of lines

1,2 , and 5 but might not be feasible for the gages of 1 ines 3 and 4 . 
the laboratory to assure that their thermal expansions match sufficiently. The gage cable and compensating cable can be located within a few centimeters of each other so the temperature distribution along them can be expected to be the same.

\section{Summary}

In this paper equations have been derived for calculating systematic errors introduced by the LNG tank environment. If appropriate measurements, especially temperature distribution measurements, are made the corrections could be calculated. The time variation of the parameters needed to correct the tank systematic error and the large number of measurements required make calculated corrections difficult.

Two relatively simple installation methods have been described in this paper that greatly reduce or eliminate tank systematic level gaging errors.

[1] Roder, H. M., ASRDI Oxygen Technology Survey Volume V: Density and Liquid Leve] Measurement Instrumentation for Cryogenic Fluids 0xygen, Hydrogen, and Nitrogen, NASA SP-3083 (1974).

[2] M. P. Wilson, Jr., AGA Operating Section Proceedings, Proceedings of the Transmission Conference, Las Vegas, Nevada, T-223, American Gas Assoc., Arlington, Va., (1976).

[3] G. Halverson, Instrumentation in Cryogenic Industry I, Houston, Texas, paper 602, Instrument Society of America, Pittsburg, Pa. (1976).

[4] C. Eilers, Proceedings, 55th International School of Hydrocarbon Measurement, Norman, 0k1ahoma, page 345. Available from Laurence S. Reid, P.0. Box 1188, Norman 0kla. (1980).

[5] R. A. Williams, Proceedings 55th International School of Hydrocarbon Measurement, Norman, 0klahoma, page 332. Available from Laurence S. Reid, P.0. Box 1188, Norman, Okla. (1980).

[6] P. B. Watson, J. Inst. Pet. 58, 126 (1972).

[7] P. Jelffs, J. Inst. Pet. $\underline{58}, 118$ (1972). 
APPENDIX B

Determination of Reference

Mark Separations on the

Calibration Tape 
The tape was hung in the shaft so the last entry in the report of calibration (following page) was at the top. The table must be inverted to give the distances of each scribe line below the top one which gives:
$0.0 \mathrm{~m}$
$5.07048 \mathrm{~m}$
$10.87539 \mathrm{~m}$
$16.66045 \mathrm{~m}$
$22.43954 \mathrm{~m}$
$31.03509 \mathrm{~m}$

for the spacings.

For this tape the elastic change is

$$
\Delta \mathrm{L} / \mathrm{L}=2.061310^{-5} \cdot \mathrm{M}
$$

where $M$ is the mass in kilograms.

The weight on the bottom of the tape was $5.245382 \mathrm{~kg}$. The average mass $M$ acting on a section of the cable is

$$
M=5.245382+(31-L / 2)(.026762) \mathrm{kg}
$$

where $L$ is the length of the section being corrected for tension. The second term is the correction for the weight of the tape. Since the tape was calibrated with a $10 \mathrm{~kg}$ weight supplying the tension, from eq (1) the corrected length in meters is:

$$
L_{C}=L\left(1+2.0613 \times 10^{-5} \times[M-10 \mathrm{~kg}]\right) .
$$

The corrected length is less than $L$ since $M$ is smaller than $10 \mathrm{~kg}$. The temperature correction is less than $0.1 \mathrm{~mm}$ for $31 \mathrm{~m}$ and not included.

The scribe mark separations, $L_{c}$ from the topmost are taken to be

$$
\begin{array}{r}
5.0701 \mathrm{~m} \\
10.8745 \mathrm{~m} \\
16.6590 \mathrm{~m} \\
22.4376 \mathrm{~m} \\
31.0324 \mathrm{~m}
\end{array}
$$

for these tests. These values are converted to the reference level separations by appropriately adding or subtracting the differences of the offsets of the scribe marks from the reference surfaces. The offsets were measured to about $0.1 \mathrm{~mm}$ with a steel machinist's scale. 
For: One Invar Tape

Submitted by: James D. Siegwarth

Division 773.10

NBS Boulder

Boulder, CO 80303

The tape was calibrated using a helium-neon laser interferometer as the length standard while under tension and uniformly supported on a horizontal flat surface. The distances between the terminal points of the indicated intervals at 20 degrees Celsius (68 degrees Fahrenheit) under 10 kilograms tension are given below. The terminal points of the indicated intervals are the centers of the graduations at the edge of the tape ribbon nearest the observer when the zero graduation is to the left.

$\begin{array}{cr}\begin{array}{c}\text { Tension } \\ \text { (kilograms) }\end{array} & \begin{array}{c}\text { Length } \\ \text { (meters) }\end{array} \\ 10 & 8.59555 \\ 10 & 14.37464 \\ 10 & 20.15970 \\ 10 & 25.96461 \\ 10 & 31.03509\end{array}$

Al1 measurements were made in a controlled environment near 20 degrees Celsius and an assumed coefficient of thermal expansion of 0.0000004 per degree was used to correct the lengths to 20 degrees.

The uncertainty of the reported lengths is 0.000005 meter per meter and is taken to be the sum of the random and systematic components of error. The random component is taken to be three times the observed standard deviation. The systematic component consists solely of the uncertainty of the laser interferometer and is estimated to be 0.000002 meter per meter.

Measurements were made by

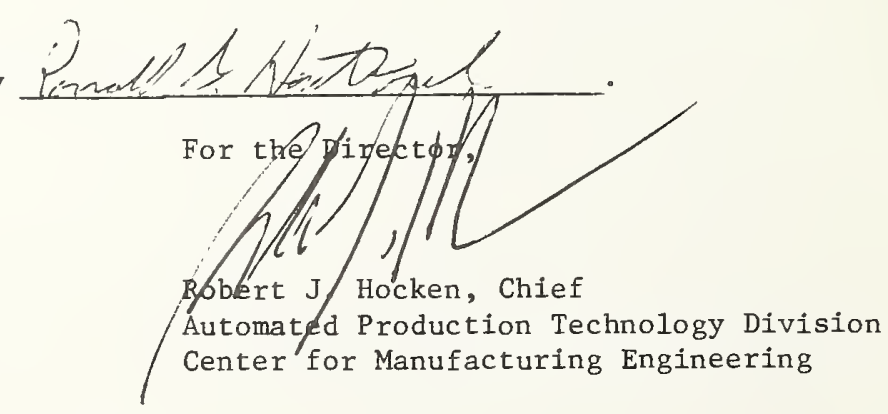

Date: June 4, 1981 
NBS.114A (REV. 2-8C)

U.S. DEPT. OF COMM.

BIBLIOGRAPHIC DATA

SHEET (See instructions)

1. PUBLICATION OR
REPORT NO.
NBSIR $82-1668$

3. Publication Date

June 1982

4. TITLE AND SUBTITLE

Measurement Uncertainties

of Level Gages for

Liquefied Natural Gas

\section{5. $\operatorname{AUTHOR}(S)$}

J. D. Siegwarth

6. PERFORMING ORGANIZATION (If joint or other than NBS, see instructions)

7. Contract/Grant No.

NATIONAL BUREAU OF STANDARDS

DEPARTMENT OF COMMERCE

WASHINGTON, D.C. 20234

9. SPONSURING ORGANIZATION NATE AND COMPLETE ADDRESS (Street, City, State, ZIF)

Maritime Administration

Department of Commerce, Washinģton, D.C.

10. SUPPLEMENTARY NOTES

[ Document describes a computer program; SF-185. FIPS Software Summary, is attached.

11. ABSTRACT (A 200-word or less factual summary of most significant information. If document includes a significant bibliography or literature survey, mention it here)

The measurement uncertainties of three types of gages commonly used in large liquefied natural gas storage and ship transport tanks have been studied and the results of this study are reported here. The types are bubbler, capacitance, and cable gages. Measurement uncertainties for various types can be determined but the test conditions must be carefully specified because many of the largest errors result from parameters external to the gaging device. The gage installation, the tank design, and the liquid properties all influence gaging accuracy. A modification of cable gage installations that should significantly improve gaging accuracy is presented. Intrinsic accuracies of some representative cable gages are reported from tests done at ambient temperature under nearly isothermal conditions. The gages tested, if calibrated, can all measure level to about one $\mathrm{mm}$ under the test conditions. Capacitance gages should be tested in liquefied natural gas to establish their measurement uncertainty. Bubbler gages require knowledge of liquid density, the temperature distributions in and contents of the connecting tubes, pressure drops, and head corrections; otherwise, the errors can be several centimeters.

12. KEY WORDS (Six to twelve entries; alphabetical order; capitalize only proper names; and separate key words by semicolons) bubbler gage; cable gage; capacitance gage; level gage; liquefied natural gas

13. AVAILABILITY

[X] Unlimited

$\square$ For Official Distribution. Do Not Release to NTIS

$\square$ Order From Superintendent of Documents, U.S. Government Printing Office, Washington, D.C. 20402.

$\underline{X} \bar{X}$ Order From National Technical Information Service (NTIS), Springfield, VA. 2216I
14. NO. OF

PRINTED PAGES

52

15. Price

$\$ 9.00$ 


